Gabrielle Scattolin

\title{
EFEITo DO Docetaxel E DA DEXAMETASONA NAS PROPRIEDADES MECÂNICAS E NA Histologia DOS Pulmỗes
}


Universidade de Brasília - UnB

Faculdade de Medicina - FM

Pós-Graduação em Ciências Médicas

Laboratório de Fisiologia Respiratória Experimental

\section{EFEITo DO Docetaxel E DA DEXAMETASONA NAS PROPRIEDADES MecÂnicAs E NA Histologia dOS PulmÕes}

Mestranda: Gabrielle Scattolin

Orientador: Prof. Dr. César Augusto Melo e Silva

Tese Apresentada ao Programa de Pós-Graduação em Ciências Médicas da Universidade de Brasília - UnB como Parte dos Requisitos Exigidos para a Obtenção do Grau de Mestre em Ciências Médicas. 
"A percepção do desconhecido é a mais fascinante das experiências. O homem que não tem os olhos abertos para o misterioso passará pela vida sem ver nada."

Albert Einstein 


\section{Dedicatória}

À minha família, esposo e filha, por serem meu porto seguro e a razão da minha caminhada. Aos meus pais pela educação, incentivo e exemplo. 


\section{Agradecimentos}

Para a elaboração e execução dessa tese, a cooperação de algumas pessoas foi fundamental. A elas expresso meu profundo agradecimento:

- Ao meu orientador César Augusto Melo e Silva pela imensa ajuda em todas as fases do meu projeto e acima de tudo pela amizade e paciência. Seu exemplo ficará para sempre na minha trajetória profissional.

- Aos professores Eduardo Gaio e Veronica Amado pelo co-orientação, aperfeiçoando as nossas ideias, e principalmente pelo acolhimento e amizade.

- Aos colegas do laboratório de fisiologia respiratória por dividirem as expectativas e anseios.

- Ao amigo Dr. Carlos Alberto Carneiro Rangel de Castro pelo pioneirismo na nossa linha de pesquisa.

- A Sra. Glória, que gentilmente confeccionou as lâminas para análise morfológica.

- Ao técnico do laboratório de fisiologia respiratória Sr. José Tavares dos Santos por viabilizar a logística com os animais. 


\section{Resumo}

Introdução: A prevalência estimada de pneumonia induzida por docetaxel é de 10\% sendo fatal em 40\% dos casos e os corticóides são rotineiramente utilizados para reduzir a incidência de náuseas, vômitos e de síndrome de retenção hídrica induzida pelos taxanes. Contudo, são escassos os estudos que avaliam se o seu uso é capaz de reduzir os efeitos deletérios do docetaxel aos pulmões. Objetivo: avaliar se a dexametasona é capaz de atenuar as alterações mecânicas do sistema respiratório e da morfologia do tecido pulmonar de ratos expostos ao docetaxel. Métodos: 64 ratos da raça wistar foram divididos em 8 grupos de acordo com as doses de docetaxel administradas $\left(0,70,140\right.$ e $210 \mathrm{mg} \cdot \mathrm{m}^{-2}$ ) e a dexametasona (quando aplicada) foi administrada na dose de $5 \mathrm{mg} \cdot \mathrm{kg}^{-1}$ concomitantemente com o docetaxel e após 24 e 48 horas da primeira dose. Após 4 semanas, foram avaliadas a impedância do sistema respiratório e dos pulmões, e a morfologia do tecido pulmonar. Resultados: O docetaxel aumentou a elastância estática do sistema respiratório $(p=0,04)$, a dissipação $(p<0,001)$ e a conservação de energia no tecido pulmonar $(p=0,024)$, e a deposição do colágeno no parênquima pulmonar $(p<0,001)$ sem quaisquer efeitos protetores da dexametasona para estas variáveis. Houve interação entre docetaxel/dexametasona no aumento do depósito de fibras colágenas nos vasos pulmonares $(p=0,04)$. Conclusões: À exceção do remodelamento vascular pulmonar, a dexametasona não atenuou o aumento da impedância do sistema respiratório, dos pulmões, e da deposição de colágeno no parênquima pulmonar após administração única de docetaxel.

Palavras-chave: remodelamento vascular; remodelamento do parênquima pulmonar; impedância do sistema respiratório; modelo de fase constante; técnica de oscilação forçada. 


\section{Abstract}

Rationale: the estimated prevalence of docetaxel-induced pneumonia is $10 \%$ being fatal in $40 \%$ of the cases and the corticosteroids are routinely administered in clinical practice to reduce the incidence of taxane-induced nausea, vomiting and fluid retention syndrome. However, there are few studies that evaluate whether its use can reduce the deleterious effects of docetaxel to the lungs. Objective: to evaluate whether the dexamethasone can mitigate the alterations of the respiratory system mechanical properties and lung tissue morphology of rats exposed to docetaxel. Methods: 64 male wistar rats were divided into 8 groups according to the docetaxel doses $\left(0,70,140\right.$, and $\left.210 \mathrm{mg} \cdot \mathrm{m}^{-2}\right)$ and dexamethasone $\left(5 \mathrm{mg} \cdot \mathrm{kg}^{-1}\right.$, when applied) was concomitantly administered with the docetaxel and 24 and 48 hours after the first dose injected. After 4 weeks the respiratory system and lung's impedances and the lung tissue morphology were evaluated. Results: The docetaxel increased the respiratory system elastic elastance $(p=0,04)$, the energy dissipation $(p<0,001)$ and conservation $(p=0,024)$ in the lung tissue, and the collagen fiber deposition in the lung parenchyma $(p<0,001)$ without any protection effects of the dexamethasone for these variables. There was an interaction effect of docetaxel/dexamethasone on the collagen fiber deposition in the lung vasculature $(p=0,04)$. Conclusions: Except to the lung vascular remodeling, the dexamethasone did not mitigate the docetaxel-induced increase of the respiratory system and lung impedances was well as the collagen deposition in the lung parenchyma.

Key-words: vascular remodeling; lung parenchyma remodeling; respiratory system impedance; constant-phase model; forced oscillation technique. 


\section{Sumário}

Dedicatória .................................... iii

Agradecimentos . . . . . . . . . . . . . . . . . . iv

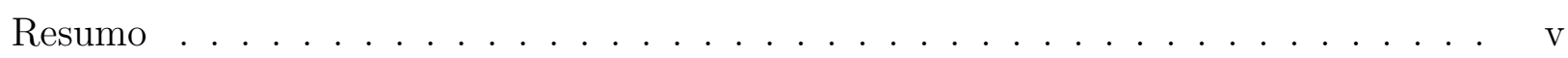

Abstract ..................................... vi

Lista de Figuras $\quad$ ix

Lista de Tabelas $\quad$ xi

Lista de Abreviaturas $\quad$ xii

$\begin{array}{llr}1 & \text { Introdução } & 1\end{array}$

1.1 O câncer como um problema de saúde pública . . . . . . . . . . . . . . . 1

1.2 História e importância do taxanes $\ldots \ldots \ldots \ldots \ldots \ldots \ldots \ldots \ldots$

1.3 Pneumonia induzida por docetaxel $\ldots \ldots \ldots \ldots \ldots \ldots$

1.4 Influência dos corticoides na profilaxia da pneumonia induzida pelo docetaxel . . 7

$\begin{array}{llr}2 & \text { Objetivos } & 8\end{array}$

\begin{tabular}{llr}
\hline & Material e Métodos & 9
\end{tabular}

3.1 Animais utilizados $\ldots \ldots \ldots \ldots \ldots$

3.2 Caracterização dos grupos $\ldots \ldots \ldots \ldots \ldots$

3.3 Protocolo experimental $\ldots \ldots \ldots \ldots \ldots \ldots \ldots$

3.4 Medidas In Vivo da resistência e da elastância do sistema respiratório . . . . . . 13

3.5 Medidas In Vivo da impedância do sistema respiratório e das propriedades mecânicas do tecido pulmonar. . . . . . . . . . . . . . . . . . . . . . . . . 15

$3.6 \quad$ Análise morfométrica do tecido pulmonar . . . . . . . . . . . . . . . . . . . . 19

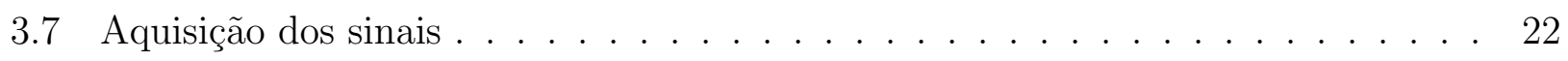


3.8 Análise estatística $\ldots \ldots \ldots \ldots \ldots \ldots$. . . . . . . . . . . . . . . . . . . 22

\begin{tabular}{|lll}
\hline 4 & Resultados & 24
\end{tabular}

4.1 Peso dos animais . . . . . . . . . . . . . . . . . . . . . . . 24

4.2 Resistência e elastância do sistema respiratório . . . . . . . . . . . . . . . 26

4.3 Impedância do sistema respiratório e propriedades mecânicas do tecido pulmonar 27

4.4 Morfologia do tecido pulmonar . . . . . . . . . . . . . . . . . . . . . . . . 31

\begin{tabular}{|llr}
5 & Discussão & 38 \\
\hline
\end{tabular}

5.1 Considerações gerais acerca do modelo experimental utilizado . . . . . . . . . . 39

5.2 Avaliação do peso corporal . . . . . . . . . . . . . . . . . . . . . . . 42

5.3 Correlação entre as propriedades mecânicas do sistema respiratório e os achados histológicos . . . . . . . . . . . . . . . . . . . . . 4 43

5.4 Mecanismo fisiopatológico da lesão pulmonar induzida pelo docetaxel . . . . . 47

5.5 Efeito do corticoide nas propriedades mecânicas pulmonares e nos achados histológicos . . . . . . . . . . . . . . . . . . . . . . . . . 48

5.6 Críticas ao estudo . . . . . . . . . . . . . . . . . . . . . . . . 50

\begin{tabular}{lll}
\hline & Conclusões & 52
\end{tabular}

\begin{tabular}{ll}
\hline Referências Bibliográficas & 53
\end{tabular}

\begin{tabular}{|l|l}
\hline Appendices & 65
\end{tabular}

Apêndice A Aprovação da Comissão de Ética no Uso de Animais 65 


\section{Lista de Figuras}

1.1 Microtubúlo . . . . . . . . . . . . . . . . . . . . . . . . . . . . . . 3

1.2 Formação, estrutura e estabilização dos microtúbulos $\ldots \ldots \ldots \ldots$. . . . . . 4

3.1 Manobra de insuflação pulmonar a $30 \mathrm{cmH}_{2} \mathrm{O} \ldots \ldots \ldots$

3.2 Técnica de oscilação forçada de 1 freqüência $\ldots \ldots \ldots$. . . . . . . . . . . 13

3.3 Modelo linear unicompartimental . . . . . . . . . . . . . . . . . . . . . 14

3.4 Técnica de oscilação forçada de múltiplas freqüências $\ldots \ldots \ldots \ldots$. . . . . . 17

3.5 Quantificação do percentual de fibras colágenas no parênquima pulmonar realizada com o Image J . . . . . . . . . . . . . . . . . . 20

$3.6 \quad$ Sistema teste coerente para análise morfométrica do tecido pulmonar . . . . . . 21

4.1 Peso dos animais no momento no qual foram administradas a soluções salina, e ou de dexametasona e ou de docetaxel anidro nas diferentes doses . . . . . . . . 24

4.2 Efeito da administração do docetaxel anidro no peso dos animais. . . . . . . . . 25

4.3 Efeito da administração da dexametasona no peso dos animais . . . . . . . . . . 26

4.4 Efeito da administração do docetaxel anidro na elastância do sistema respiratório 27

4.5 Espectro da impedância do sistema respiratório . . . . . . . . . . . . . . . . 28

$4.6 \quad$ Efeito da administração do docetaxel anidro na resistência Newtoniana . . . . . 29

4.7 Efeito da administração do docetaxel anidro na dissipação de energia no tecido

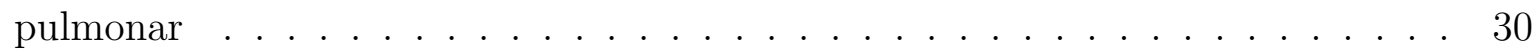

4.8 Efeito da administração do docetaxel anidro na conservação de energia no tecido pulmonar . . . . . . . . . . . . . . . . . . 31

4.9 Percentual de fibras colágenas no parênquima pulmonar . . . . . . . . . . . 32

4.10 Efeito da interação docetaxel anidro $x$ dexametasona no percentual de fibras colágenas na vasculatura pulmonar $\ldots \ldots \ldots \ldots$ 
4.11 Efeito principal simples do docetaxel anidro no percentual de fibras colágenas na vasculatura pulmonar dos animais que não receberam a dexametasona . . . . . . 34

4.12 Efeito principal simples do docetaxel anidro no percentual de fibras colágenas na vasculatura pulmonar dos animais que receberam a dexametasona . . . . . . . . 35

4.13 Efeito da administração do docetaxel anidro no índice de edema alveolar . . . . 36

4.14 Efeito da administração da dexametasona anidro no índice de edema alveolar . . 37 


\section{Lista de Tabelas}

4.1 Resistência do sistema respiratório $\ldots \ldots \ldots$. . . . . . . . . . . . 26 


\section{Lista de Abreviaturas}

$\begin{array}{ll}A & \text { Amplitude } \\ A_{\text {in }} & \text { Amplitude de entrada } \\ A_{\text {out }} & \text { Amplitude de saída }\end{array}$

ANOVA Análise de variância

$\mathrm{Ca}^{+2} \quad$ Cálcio

COD Coeficiente de determinação

CTRL Controle

DCT Docetaxel

$\Delta P \quad$ Variação de pressão

DEXA Dexametasona

DF Distrito Federal

DL Dose letal

E Elastância

$E_{r s} \quad$ Elastância do sistema respiratório

F $\quad$ Estatística $F$

f $\quad$ Freqüência

G Amortecimento tecidual no modelo de fase constante

$H \quad$ Armazenamento de energia no tecido pulmonar no modelo de fase constante

HE Hematoxilina-eosina

I Inertância

IARC Agência Internacional para Pesquisa em Câncer 


\begin{tabular}{|c|c|}
\hline IB & Instituto de Biologia \\
\hline IC & Intervalo de confiança \\
\hline IEA & Índice de edema alveolar \\
\hline $\mathrm{Mg}^{+2}$ & Magnésio \\
\hline OMS & Organização Mundial de Saúde \\
\hline$P$ & Pressão \\
\hline PAM & Proteínas associadas a microtúbulos \\
\hline$P_{a o}$ & Pressão na abertura das vias aéreas \\
\hline$P_{c y l}$ & Pressão no cilindro \\
\hline PEEP & Pressão positiva ao final da expiração \\
\hline$P_{e l}$ & Pressão de recolhimento elástico \\
\hline $\mathrm{R}$ & Resistência \\
\hline$R_{N}$ & Resistência Newtoniana \\
\hline$R_{r s}$ & Resistência do sistema respiratório \\
\hline $\mathrm{SC}$ & Superfície corporal \\
\hline sen & seno \\
\hline SP & São Paulo \\
\hline$t$ & Tempo \\
\hline TFG & Trifosfato de guanosina \\
\hline TOF & Técnica de oscilação forçada \\
\hline $\mathrm{UnB}$ & Universidade de Brasília \\
\hline$\dot{V}$ & Fluxo \\
\hline
\end{tabular}


Volume

$X$

Reatância

$Z$

Impedância

$Z_{r s}$

Impedância do sistema respiratório

$\alpha$

Expoente da freqüência no modelo de fase constante

$\eta^{2}$ parcial Tamanho do efeito

$\omega \quad$ Freqüência angular

$\phi_{\text {in }} \quad$ Fase de entrada

$\phi_{\text {out }} \quad$ Fase de saída 
$\sum_{\text {cosurue }} 1$

\section{Introdução}

\subsection{O câncer como um problema de saúde pública}

O Brasil vem sofrendo mudanças em seu perfil demográfico, conseqüência, entre outros fatores, do processo de urbanização populacional, da industrialização e dos avanços da ciência e da tecnologia. Estas novas características da sociedade brasileira, unem-se os novos estilos de vida e a exposição, ainda mais intensa, a fatores de risco próprios do mundo contemporâneo.

Esse processo de mudança demográfica, denominado "envelhecimento" da população, associado a transformação nas relações entre as pessoas e seu ambiente, trouxe uma alteração importante no perfil de morbimortalidade, diminuindo a ocorrência de doenças infecto contagiosas e colocando as doenças crônico degenerativas como novo centro de atenção aos problemas de doença e morte da população.

De acordo com as estimativas mundiais do projeto Globocan 2012, da Agência Internacional para Pesquisa em Câncer (IARC), da Organização Mundial de Saúde (OMS), houve 14,1 milhões de casos novos de câncer e um total de 8,2 milhões de mortes por câncer, em todo o mundo, em 2012.1,2 A carga de câncer continuará aumentando nos países em desenvolvimento e aumentará ainda mais nos países desenvolvidos se medidas preventivas não forem amplamente aplicadas. Nesses, os tipos de cânceres mais freqüentes na população masculina foram próstata, pulmão e colorretal; e mama, colorretal e pulmão entre as mulheres. Nos países em desenvolvimento os três mais freqüentes em homens foram pulmão, estômago e fígado; e mama, colo do 
útero e pulmão em homens., ${ }^{1,2}$

Ainda de acordo com a mesma fonte, em 2030, a carga global será de 21,4 milhões de casos novos de câncer e 13,2 milhões de morte de mortes por câncer, em conseqüência do crescimento e envelhecimento da população. ${ }^{1,2}$ No Brasil, segundo dados do Instituto Nacional do Câncer - Ministério da Saúde, a estimativa para o ano de 2014, que será válida também para o ano de 2015, aponta para a incidência de aproximadamente 576 mil casos novos de câncer. ${ }^{1}$

É incontestável que o câncer é hoje um problema de saúde pública, sendo necessário aprimorar as medidas de controle e prevenção e as medidas para tratamento. Embora uma grande parte destes pacientes possa ser tratada com cirurgia exclusiva, outros receberão diagnóstico em fase avançada, aumentando grandemente os custos e complicações decorrentes do tratamento, ainda, utilizando quimioterapia como forma básica de controle da doença.

\subsection{História e importância do taxanes}

Em 1971, Horwiz e colaboradores demonstraram que o produto natural paclitaxel, derivado da casca das plantas taxus brevifolia e taxus baccata, era capaz de estabilizar microtúbulos, impedindo a despolimerização necessária à replicação celular, bloqueando assim, o processo de divisão celular. ${ }^{3,4}$

Os microtúbulos são constituídos por proteínas heterodiméricas, compostas por duas subunidades: $\alpha$ e $\beta$ tubulina, de aproximadamente 440 aminoácidos cada uma, com peso molecular de aproximadamente 50 KD. A tubulina está presente em todas as células eucariotas existindo sob forma heterodimérica $\alpha$ e $\beta$ ou microtubular. ${ }^{3}$

As duas subunidades são organizadas entre si por ligações de hidrogênio pela região $\mathrm{CO} 2 \mathrm{H}$ terminal da subunidade $\beta$ e da região $\mathrm{NH} 2$ da subunidade $\alpha$, sendo a formação dos microtúbulos realizadas pelo rearranjo regular em cilindros flexíveis obtidos em duas etapas: iniciação e elongação. ${ }^{3}$

Os microtúbulos (Figura 1.1) são absolutamente necessários ao processo de divisão celular, e são utilizados pelas células para formar a estrutura estática chamada de citoesqueleto, o qual dá forma às células e determina a posição das organelas. ${ }^{3,4}$ Suas propriedades dinâmicas 
são usadas para transmitir sinais celulares, reorganizar organelas, proporcionar mobilidades às células, intervir no processo de secreção células e na comunicação neuronal, o que explica a sua abundância nos neurônios. Devido à sua versatilidade, uso e importância no crescimento celular, os microtúbulos têm sido considerados importantes alvos subcelulares para atuação de agentes quimioterápicos..$^{3,4}$

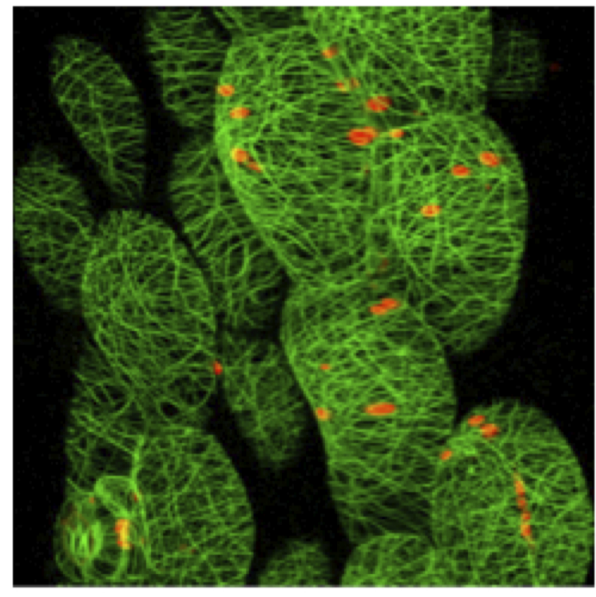

Figura 1.1: Foto do microtúbulo (Leica systems TCS)

Estruturalmente, os microtúbulos são arranjados de forma cilíndrica, contendo 17 protofilamentes e apresentando um diâmetro de $24 \mathrm{~nm}$, como ilustrado na figura 1.2. A iniciação e elongação dos protofilamentes ocorre em presença de proteínas associadas aos microtúbulos (PAM), $\mathrm{Mg}^{+2}$ e trifosfato de guanosina (TFG), sendo o processo reversível em presença de $\mathrm{Ca}^{+2}$ a $0^{\circ} \mathrm{C}^{3}$ Em presença de paclitaxel ocorre a estabilização dos núcleos $\alpha$ e $\beta$ tubulinas pela intercalação deste fármaco resultando, assim, em distúrbio na formação do microtúbulo. 3,4 


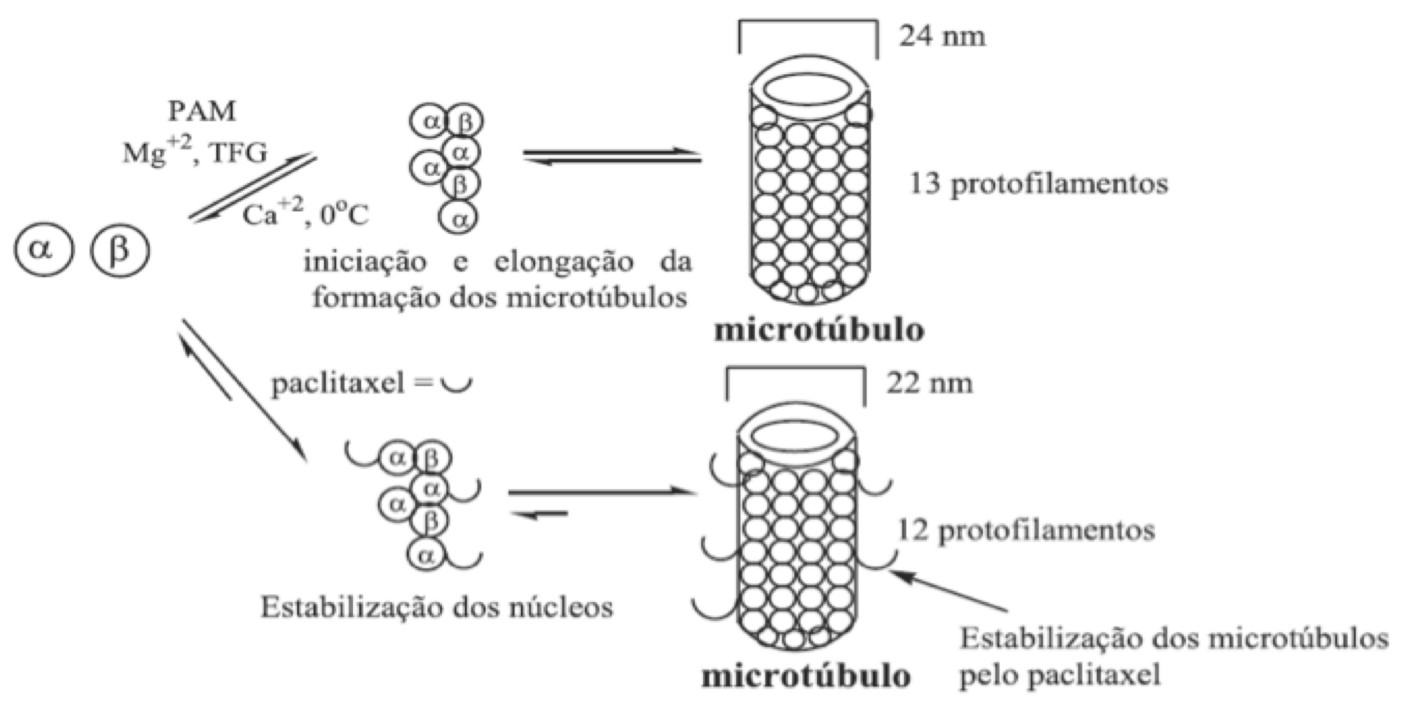

Figura 1.2: Formação, estrutura e estabilização dos microtúbulos

Um grande problema na extração do paclitaxel reside no fato de que a espécie taxus brevifolia demora de 100 a 200 anos para atingir a maturidade, além de encontrar-se em extinção. Para a obtenção de $1 \mathrm{Kg}$ do paclitaxel são necessários $10.000 \mathrm{Kg}$ da casca da taxus brevifolia, sendo necessário abater cerca de 3000 árvores. ${ }^{3}$

Graças ao sucesso terapêutico e econômico do paclitaxel (Taxol` ${ }^{\circledR}$ ) que gerou um faturamento de 1,6 bilhões de dólares no ano 2000 para a empresa produtora, inúmeros análogos foram sintetizados em laboratório, por diferentes grupos de pesquisa, com objetivo de identificar os grupos farmacológicos (responsáveis pela atividade biológica), estabelecendo assim, a relação estrutura-atividade na tentativa de obter fármacos mais potentes. Com isto, em 1986 foi descoberto o docetaxel, que é, em alguns casos, 1,6 vezes mais ativo que o paclitaxel. . $^{3,4}$

Tanto o docetaxel como o paclitaxel possuem o mesmo mecanismo de ação, ou seja, ambos promovem ligação estável com a tubulina e inibem a despolimerização dos microtúbulos. Ainda, seu mecanismo de ação independe da presença de quaisquer cofatores. ${ }^{3-5}$

Embora tenham sido descobertos há pouco tempo, os taxanes são uma classe de medicamento amplamente utilizados para tratamento do câncer, compondo o esquema quimioterápico de primeira escolha para câncer de pulmão, mama, próstata, estômago e cabeça e pescoço, tanto como droga única como em combinação com outros fármacos. Devido ao seu uso disseminado, e a maior experiência no seu manuseio, vários efeitos colaterais significativos tem sido descritos, 
cada vez com maior freqüência. ${ }^{6-13}$

\subsection{Pneumonia induzida por docetaxel}

Em geral o docetaxel possui uma boa tolerância. Entretanto, por ser uma droga de uso recente, pouco se sabe sobre a sua farmacocinética e seus efeitos adversos. Alguns são hipersensibilidade, dermatite, onicólise, mucosite, mialgia e toxicidade pulmonar, sendo a maioria deles descritos recentemente. ${ }^{13,14}$ Ademais, pouco se conhece acerca dos efeitos crônicos da droga em seres vivos, seja pela ausência de tempo suficiente de seguimento clínico, seja pela falta de modelos experimentais de estudo.

A toxicidade pulmonar induzida por quimioterápicos não é novidade na prática clínica. A lesão por bleomicina, por exemplo, é bem conhecida e serve de modelo experimental de fibrose pulmonar idiopática. ${ }^{15,16}$

Vários são os mecanismos descritos para toxicidade pulmonar induzida por fármacos, tais como:

Lesão oxidativa: usualmente, moléculas oxidativas que são produzidas dentro de células fagocitárias (monócitos, macrófagos e neutrófilos) participam em reações de oxirredução, resultando em oxidação de ácidos graxos, os quais instabilizam a membrana celular. Normalmente, os mecanismos de defesa celular (superóxido dismutase, peroxidases, tocoferol, dentre outros) promovem o equilíbrio necessário para prevenção da lesão. Diversas drogas agem por este mecanismo, sendo a nitrofurantoína um exemplo típico deste mecanismo. ${ }^{17}$

Dano vascular pulmonar: este mecanismo manifesta-se como edema pulmonar agudo, doença intersticial difusa aguda, oclusão vascular pulmonar, hipertensão pulmonar ou hemorragia pulmonar. O provável mecanismo fisiopatológico é por aumento da pressão hidrostática na microvasculatura, aumento da permeabilidade do endotélio vascular ou por ativação de mecanismos imunológicos ou inflamatórios. ${ }^{18}$

Depósito de fosfolipídeos intra-celular: determinadas drogas podem levar ao acúmulo de fosfolipídeos dentro dos lisossomos, devido à inibição enzimática da fosfolipase A2. O 
mecanismo usualmente é reversível com a suspensão da droga. O mecanismo de toxicidade da amiodarona pode ser citado como exemplo nesta classe. ${ }^{19}$

Lesão mediada pelo sistema imunológico: algumas drogas podem funcionar como haptenos, induzindo à ativação da cascata imunológica. Depósitos de complexo antígeno anticorpo podem desencadear a ativação da resposta inflamatória, levando à lesão celular. O lúpus eritematoso sistêmico induzido por drogas é um exemplo deste mecanismo. ${ }^{17}$

Depressão do sistema nervoso central: determinadas drogas são capazes de causar edema pulmonar neurogênico agudo por causar descarga de neurotransmissores, levando à hipertensão intra-craniana, que por sua vez pode levar a uma descarga autonômica aguda. Drogas como o naloxane, heroína, interleucina 2, citarabina ou o metotrexato aplicado por via intra-tecal podem servir para exemplificar este mecanismo. ${ }^{20}$

Efeito citotóxico direto: alguns quimioterápicos são capazes de lesar diretamente o pulmão. A bleomicina, por exemplo, é capaz de provocar lesão por dano direto aos pneumócitos tipo 1 , induzindo fibrose pulmonar (chamada de alveolite fibrosante). ${ }^{21,22}$

A pneumonia intersticial induzida por taxanes foi reportada pela primeira vez em 1997 e sua incidência vem crescendo ao longo dos anos, chegando a 10\% em alguns casos e atingindo mortalidade superior a 40\%, podendo ocorrer algumas horas após a infusão ou após várias semanas. ${ }^{16}$ Os principais fatores de risco para a sua manifestação são: associação com outros quimioterápicos, pacientes politratadaos e uso concomitante com radioterapia. São raros os relatos de pneumonia induzida por taxanes após uma única aplicação de quimioterapia. A apresentação clínica e os achados radiológicos são inespecíficos e não há uma estratégia de tratamento ou de prevenção bem estabelecidas na literatura. ${ }^{16,17}$

O mecanismo fisiopatológico da lesão pulmonar induzida pelo docetaxel também é desconhecido e várias hipóteses tem sido aventadas. A maioria dos autores atribuem os danos pulmonares a uma reação imune mediada por linfócitos.

Anteriormente ao início dos trabalhos nesta linha de pesquisa, inexistiam modelos experimentais que avaliassem, os efeitos pulmonares oriundos da exposição ao docetaxel. No trabalho conduzido no laboratório de fisiologia respiratória - UnB em 2012 foi possível compro- 
var que o docetaxel foi capaz de produzir lesão pulmonar caracterizada por depósito de fibras colágenas nos septos alveolares e no tecido pulmonar em 100\% dos ratos tratados com esta droga e ainda alterar as propriedades mecânicas do sistema respiratório.

\subsection{Influência dos corticoides na profilaxia da pneumo- nia induzida pelo docetaxel}

Na prática clínica é recomendável a utilização de glicocorticoides conjuntamente com os taxanes sendo a primeira dose administrada concomitantemente à infusão e as demais nas 48 horas subseqüentes, com a finalidade de redução da síndrome de retenção hídrica que ocorre por provável lesão ao endotélio vascular. Esta medida reduz a incidência de retenção de fluidos de 20 para $6 \%$ e aumenta a tolerabilidade ao tratamento na maioria dos casos. ${ }^{15,23,24}$ Além disto, para casos de pneumonia grave com instauração arterial e insuficiência respiratória aguda recomenda-se o tratamento com corticoides empiricamente, observando-se melhora clínica na maioria das vezes. ${ }^{15}$

Ainda, é conhecido o fato de algumas drogas antineoplásicas induzirem imunossupressão, o que pode indiretamente contribuir para injúria pulmonar. Além do efeito direto dos taxanes no parênquima pulmonar gerando fibrose, há descrição de indução da proliferação de linfócitos $\mathrm{T}$ citotóxicos contra antígenos pulmonares específicos expressos pelos tumores. Este mecanismo fisiopatológico pode ser influenciado pela ação imunomoduladora dos glicocorticoides, reduzindo os efeitos deletérios aos pulmões. ${ }^{25,26}$

Em 2012, foi conduzido um estudo experimental no laboratório de fisiologia pulmonar da UnB, nesta mesma linha de pesquisa, onde foi observada lesão pulmonar induzida pelo Docetaxel, caracterizada por acúmulo de fibras colágenas no pulmão em 100\% dos ratos expostos, mas em contrapartida, a prevalência de pneumonia induzida por este fármaco descrtita na literatura é em torno de 10\%, o que gera o questionamento: Seria o uso rotineiro de corticoides na prática clínica o motivo da discrepância entre as incidências de pneumonia induzida por docetaxel na literatura e a encontrada no estudo anterior? 
${ }_{\text {Capítulo }} 2$

\section{Objetivos}

Este trabalho teve como objetivo avaliar os efeitos da aplicação de docetaxel anidro e da dexametasona nas propriedades mecânicas do sistema respiratório, dos pulmões e na morfologia do tecido pulmonar. 


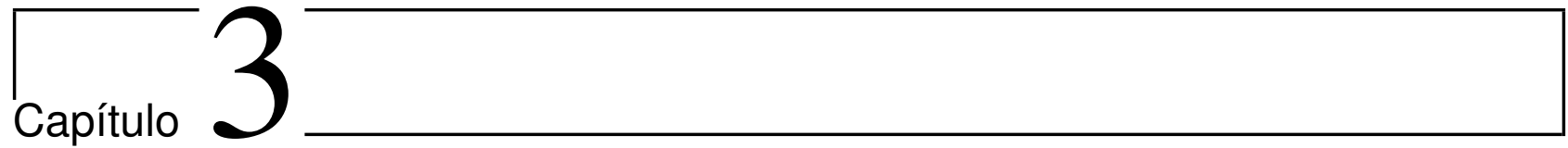

\section{Material e Métodos}

Tendo em vista que este trabalho é uma sequiência de um experimento realizado anteriormente no Laboratório de Fisiologia Respiratória - UnB, foram aproveitados os dados do estudo piloto daquele experimento que estabeleceu a dose letal de docetaxel em $50 \%$ da amostra (DL 50), que foi de 250 mg.m ${ }^{-2}$. Esta dose foi reduzida em 16\% (para adequar a DL 50 ao modelo estatístico escolhido), de forma a gerar em modelo experimental que permitisse o ajuste da dose a intervalos regulares, partindo da dose terapêutica usual do docetaxel de 70 mg.m ${ }^{-2}$ (60 - $100 \mathrm{mg} \cdot \mathrm{m}^{-2}$ ). Desta forma, as doses de quimioterápicos aplicadas foram $70 \mathrm{mg} \cdot \mathrm{m}^{-2}, 140$ mg.m ${ }^{-2}$ e 210 mg.m $\mathrm{m}^{-2}$, calculadas para superfície corporal de cada animal.

O estudo foi aprovado pelo Comitê de Ética no Uso Animal da Universidade de Brasília, Instituto de Biologia (IB) - UnB, protocolo número UnBDoc 77170/2012 (em anexo). Todo o trabalho experimental foi realizado nos laboratórios de Fisiologia Respiratória e de Histologia da Universidade de Brasília.

\subsection{Animais utilizados}

Foi realizado estudo experimental utilizando-se 64 ratos da raça Wistar, do sexo masculino, com massa entre 180 e 260 gramas de produção própria, adquiridos no laboratório BioAgri, Planaltina - DF. 


\subsection{Caracterização dos grupos}

Controle (CTRL): composto por 8 ratos, aos quais foi aplicada via intraperitoneal $10 \mathrm{~mL}$ de solução fisiológica.

Dexametasona (DEXA): composto por 8 ratos, aos quais foi aplicada, via intraperitoneal, $10 \mathrm{~mL}$ de solução fisiológica + dexametasona na dose de $5 \mathrm{mg} \cdot \mathrm{kg}^{-1} \cdot \mathrm{dia}^{-1}$, durante três dias consecutivos.

Docetaxel 70 (DCT70): composto por 8 ratos, aos quais foi aplicada, via intraperitoneal, solução de docetaxel anidro na dose de $70 \mathrm{mg} \cdot \mathrm{m}^{-2}$.

Docetaxel 70 + dexametasona (DCT70 + dexa): composto por 8 ratos aos quais foi aplicada, via intraperitoneal, solução de docetaxel anidro na dose de $70 \mathrm{mg} \cdot \mathrm{m}^{-2}+$ dexametasona na dose de $5 \mathrm{mg} \cdot \mathrm{kg}^{-1} \cdot \mathrm{dia}^{-1}$, durante 3 dias consecutivos.

Docetaxel (DCT140): Composto por 8 ratos aos quais foi aplicada, via intraperitoneal, solução de docetaxel anidro na dose de 140 mg.m ${ }^{-2}$.

Docetaxel 140 + dexametasona (DCT140 + dexa): Composto por 8 ratos aos quais foi aplicada, via intraperitoneal, solução de docetaxel anidro na dose de $140 \mathrm{mg} \cdot \mathrm{m}^{-2}+$ dexametasona na dose de $5 \mathrm{mg} \cdot \mathrm{kg}^{-1} \cdot \mathrm{dia}^{-1}$, durante 3 dias consecutivos.

Docetaxel 210 (DCT210): Composto por 8 ratos aos quais foi aplicada, via intraperitoneal, solução de docetaxel anidro na dose de $210 \mathrm{mg} \cdot \mathrm{m}^{-2}$.

Docetaxel 210 + dexametasona (DCT210+dexa): Composto por 8 ratos aos quais foi aplicada, via intraperitoneal, solução de docetaxel anidro na dose de $210 \mathrm{mg} \cdot \mathrm{m}^{-2}+$ dexametasona na dose de $5 \mathrm{mg} \cdot \mathrm{kg}^{-1} \cdot \mathrm{dia}^{-1}$, durante 3 dias consecutivos.

A dose de docetaxel foi calculada pela superfície corporal (SC) dos ratos, corrigida para mg.cm ${ }^{-2}$ pelo método proposto por Spector, ${ }^{27}$ sendo considerada a fórmula:

$$
S C=K x \text { peso }^{\frac{2}{3}}
$$


onde $K$ é a constante do rato e seu valor é de 9,6 e o peso do animal é medido em gramas. A superfície corporal é apresentada em $\mathrm{cm}^{2}$.

A dose de dexametasona administrada foi de $5 \mathrm{mg} \cdot \mathrm{kg}^{-1} \cdot \mathrm{dia}^{-1}$, sendo uma aplicação realizada imediatamente após a administração do docetaxel e as demais nos dois dias subseqüentes. Esta dose foi estabelecida utilizando-se as doses utilizadas e descritas em estudos anteriores que avaliaram a lesão pulmonar quimicamente induzida. ${ }^{28-31}$

Todos os ratos foram mantidos em ciclos de claro e escuro de 12 horas com ração e água ad libitum. Após 4 semanas, todos os animais foram pesados novamente e foram avaliadas as propriedades mecânicas do sistema respiratório, dos pulmões e a morfologia do tecido pulmonar, como descrito a seguir.

\subsection{Protocolo experimental}

Todos os animais foram pesados (balança digital Filizola MF-6, São Paulo, SP) e anestesiados com injeção intraperitoneal de cetamina (75 mg. $\left.\mathrm{kg}^{-1}\right)$ e xilazina $\left(10 \mathrm{mg} \cdot \mathrm{kg}^{-1}\right)$. Este regime promove boa anestesia para procedimentos que duram aproximadamente 30 minutos, tempo suficiente para realização dos atos cirúrgicos e experimentais utilizados neste estudo.

Uma vez anestesiados, os ratos foram traqueotomizados através de incisão cervical realizada acima do esterno, seguida de divulsão da musculatura infra-hioídea, separação da traquéia do esôfago e inserção de uma cânula metálica $(6 \mathrm{~cm}$ de comprimento, $2 \mathrm{~mm}$ de diâmetro interno e 2,5 mm de diâmetro externo), fixada à traquéia com fio de seda 3-0. Antes de serem ventilados mecanicamente, os ratos foram totalmente paralisados com injeção endovenosa de brometo de pancurônio ( $\left.5 \mathrm{mcg} \cdot \mathrm{kg}^{-1}\right)$ e, então, os animais foram conectados a um ventilador mecânico controlado por computador - FlexiVent FX (Scireq, Montréal, Canadá) e a ventilação mecânica foi iniciada. Os parâmetros ventilatórios utilizados, foram: ciclos respiratórios disparados a tempo, limitados e ciclados a volume, com fração inspirada de oxigênio de 21\%, volume corrente de $8 \mathrm{~mL} \cdot \mathrm{kg}^{-1}$, freqüência respiratória de 90 ciclos.minuto $^{-1}$ e pressão positiva ao final da expiração (PEEP) de $3 \mathrm{cmH}_{2} \mathrm{O}$.

O ventilador mecânico foi calibrado imediatamente antes dos animais serem ventilados. 
Tal calibração foi realizada registrando-se a pressão e o deslocamento do pistão do FlexiVent FX (Scireq, Montreal, Canadá) durante a sua oscilação com a cânula traqueal ocluída (calibração fechada) e, novamente, com a cânula traqueal aberta para a atmosfera (calibração aberta). Os sinais provenientes deste procedimento de calibração permitem que a compressão dentro do cilindro e a resistência ao fluxo aéreo através da tubulação do equipamento, que inclui a cânula traqueal, sejam removidos da medida de impedância do sistema respiratório $\left(Z_{r s}\right)$. Desta forma, os dados apresentados neste trabalho representam, somente, as propriedades mecânicas do sistema respiratório dos animais.

No intuito de restabelecer a história de volume pulmonar, os pulmões dos todos os animais foram insuflados três vezes a $30 \mathrm{cmH}_{2} \mathrm{O}$ a partir do nível da PEEP e, uma vez atingida, esta pressão foi sustentada por 3 segundos (Figura 3.1). A válvula expiratória do ventilador mecânico permaneceu fechada durante toda duração da manobra (6 segundos). Estas insuflações foram executadas imediatamente antes de realizarmos as medidas das propriedades mecânicas do sistema respiratório e dos pulmões, como descrito a seguir.

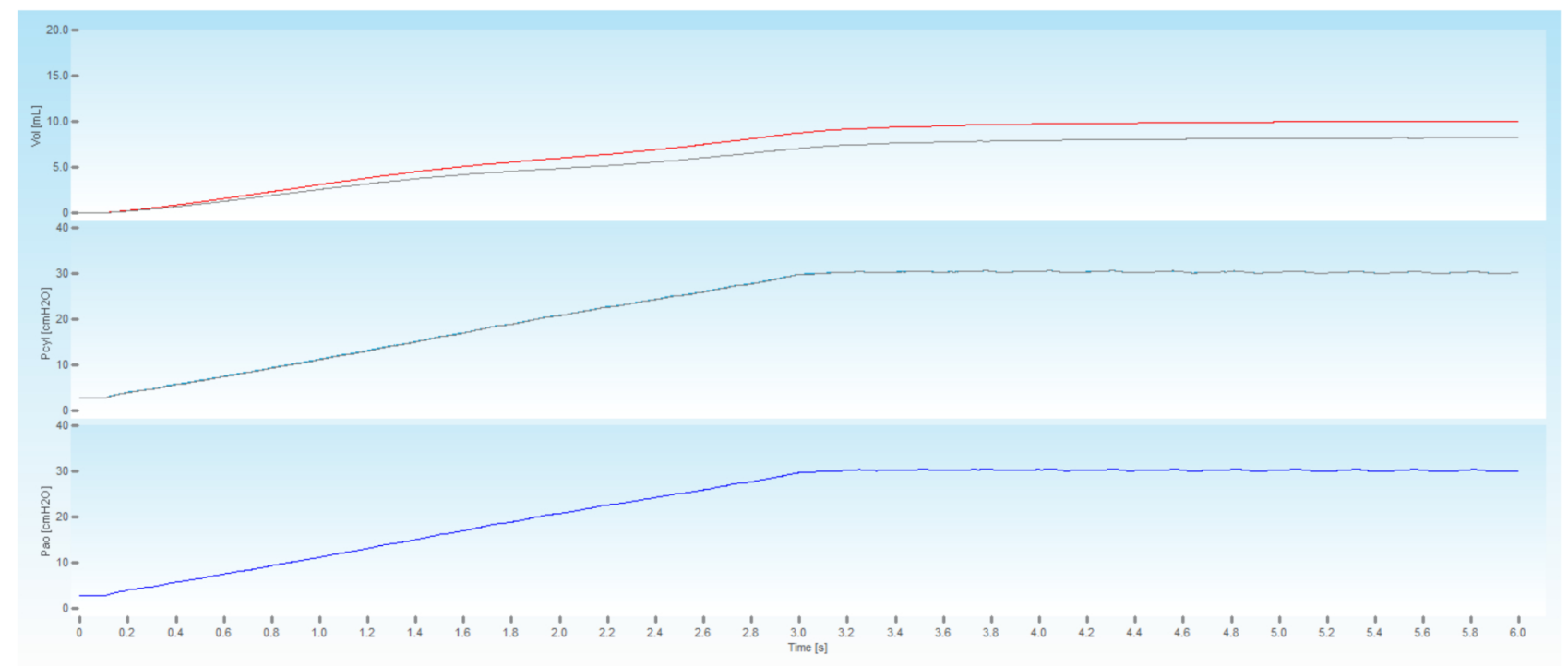

Figura 3.1: Manobra de insuflação pulmonar a $30 \mathrm{cmH}_{2} \mathrm{O}$ a partir da pressão positiva ao final da expiração realizada pelo FlexiVent FX. De cima para baixo: traçados de volume $(V)$, pressão no cilindro do ventilador mecânico $\left(P_{c y l}\right)$ e pressão na abertura das vias aéreas $\left(P_{a o}\right)$. No traçado de volume, a linha vermelha representa o volume no cilindro do ventilador mecânico e a linha cinza o volume entregue aos pulmões de um determinado rato. 


\subsection{Medidas In Vivo da resistência e da elastância do sistema respiratório}

Para a medida da resistência e da elastância do sistema respiratório ( $R_{r s}$ e $E_{r s}$, respectivamente), utilizamos a técnica de oscilação forçada (TOF) de uma única freqüência, que consiste em avaliar a resposta do sistema respiratório a uma perturbação quasi-senoidal. Esta manobra é realizada com a válvula expiratória do ventilador mecânico fechada durante a realização da perturbação (de 1,25 segundos de duração) na qual simula-se um ciclo respiratório cujos tempos inspiratório e expiratório tenham a mesma duração (Figura 3.2).

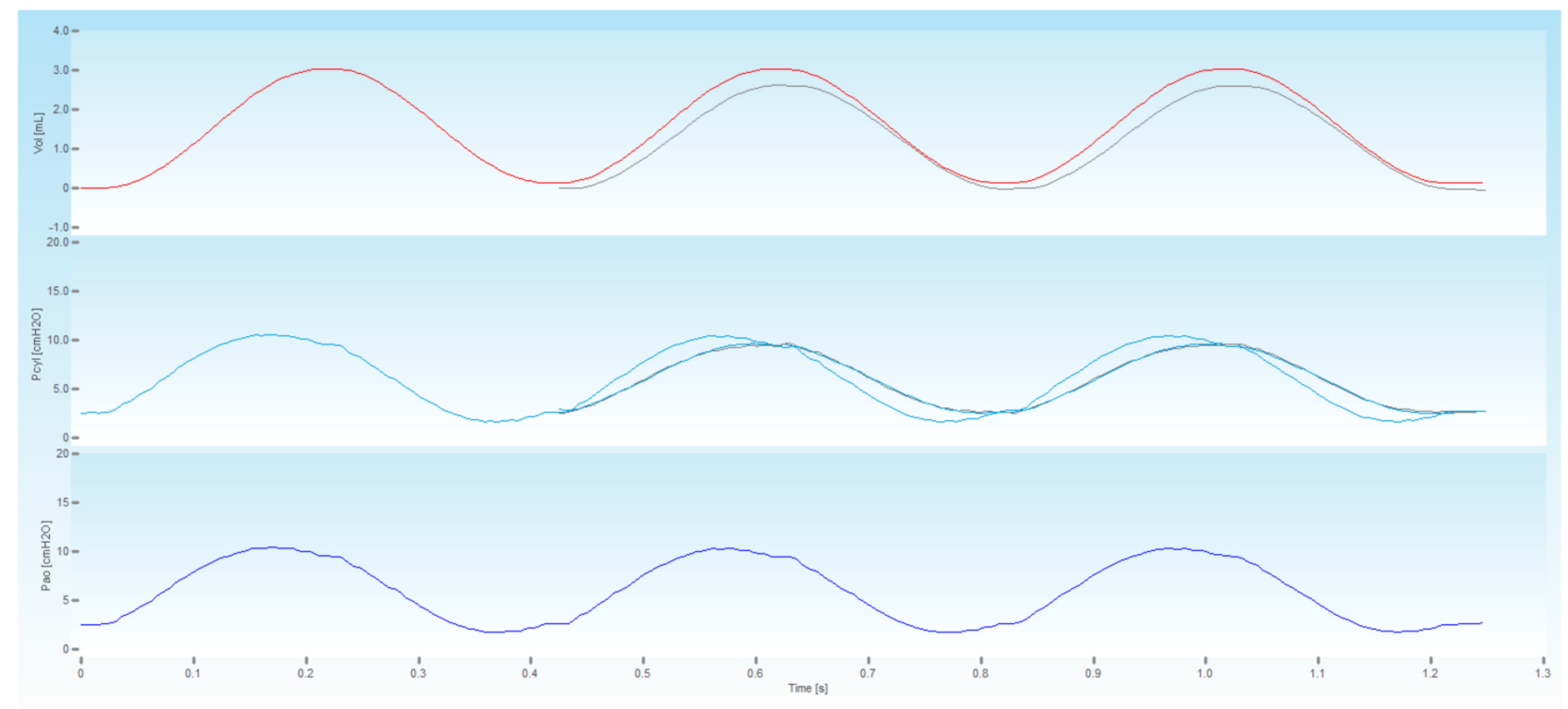

Figura 3.2: Técnica de oscilação forçada de uma única freqüência realizada pelo FlexiVent FX aplicada na abertura das vias aéreas para determinação da resistência e elastância do sistema respiratório. De cima para baixo: traçados de volume $(V)$, pressão no cilindro do ventilador mecânico $\left(P_{c y l}\right)$ e pressão na abertura das vias aéreas $\left(P_{a o}\right)$. No traçado de volume, a linha vermelha representa o volume no cilindro do ventilador mecânico e a linha cinza o volume entregue aos pulmões de um determinado rato.

Os sinais de pressão, fluxo e volume são, então, ajustados, utilizando-se regressão linear múltipla, ${ }^{32}$ à equação do movimento do modelo linear unicompartimental ${ }^{33}$ do sistema respiratório:

$$
P_{a o}(t)=R_{r s} \dot{V}(t)+E_{r s} V(t)+P_{1}
$$

onde $P_{a o}(t)$ é a pressão na abertura das vias aéreas. $R_{r s} \dot{V}(t)$ e $E_{r s} V(t)$ são os componentes resistivo e elástico do sistema respiratório, $P_{1}$ é uma estimativa da PEEP e $t$ é o tempo. 
Resumidamente, o modelo linear unicompartimental incorpora um compartimento de elastância (E) constante servido por um tubo que possui uma resistência (R) (Figura 3.3). Uma variação de pressão é necessária para movimentar o gás por esta via, de forma análoga para movimentar gás pelas vias aéreas pulmonares. Ao passo que o volume do compartimento alveolar aumenta, a mola (Figura 3.3 B) distende-se e a tensão gerada pela sua distensão produz uma pressão de recolhimento elástico $\left(P_{e l}\right)$ dentro do compartimento. Quando a pressão de distensão cessa, é esta pressão de recolhimento elástico a responsável pelo retorno do compartimento ao seu volume original, o que mimetiza a expiração passiva quando os músculos inspiratórios se relaxam ao final da inspiração.

Ainda assim, este modelo assume que (i) a $P_{e l}$ se relaciona linearmente ao volume $(V)$; (ii) a diferença de pressão $(\Delta P)$ entre as duas extremidades do tubo (Figura 3.3 A) é diretamente proporcional ao fluxo de gás $(\dot{V})$ que por ele passa; (iii) as propriedades mecânicas do sistema respiratório são independentes do $V$ e do $\dot{V}$; e (iv) as forças inerciais são desprezíveis em freqüências abaixo de $2 \mathrm{~Hz} \cdot{ }^{34}$ Em condições dinâmicas, $V$ e $\dot{V}$ são funções do tempo $(t)$.
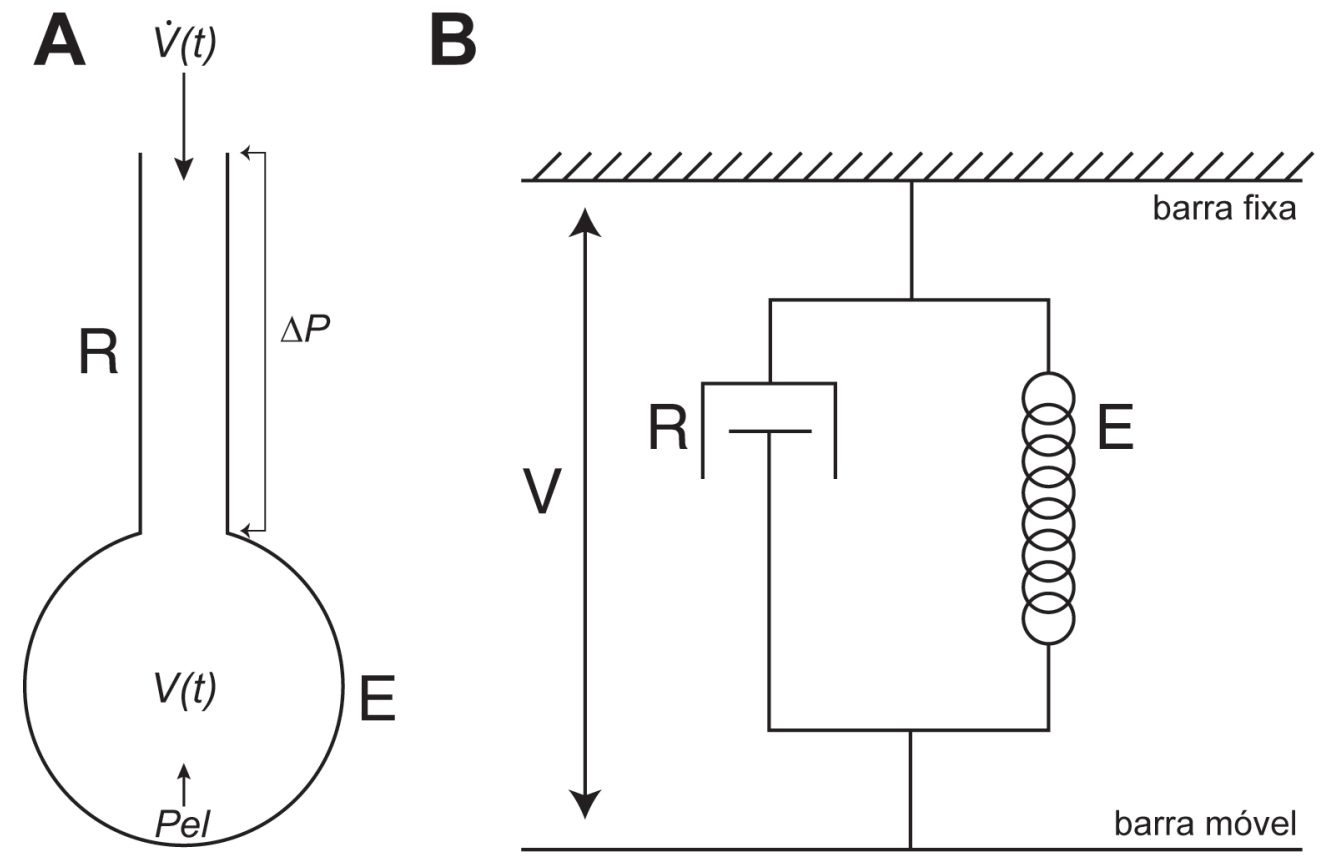

Figura 3.3: Modelo linear unicompartimental. A) Compartimento de elastância E servido por uma via de resistência $\mathrm{R} ; \dot{V}(t)$ e $V(t)$ são o fluxo e o volume em função do tempo, respectivamente; $\Delta P$ $=$ variação de pressão; $P e l=$ pressão de recolhimento elástico. B) Representação mecânica composta por uma mola de elastância E e amortecedor de resistência R; a distância entre as barras é análogo ao $V$ e a velocidade com que as barras se afastam é análogo ao $\dot{V}$.

A qualidade do ajuste do modelo pela regressão linear múltipla supracitada foi avaliada 
pelo coeficiente de determinação (COD) que, basicamente, expressa o quanto o modelo foi capaz de explicar os dados coletados. Na seção de resultados apresentamos, somente, os dados obtidos de regressões que apresentaram COD $\geq 95 \%$.

\subsection{Medidas In Vivo da impedância do sistema respira- tório e das propriedades mecânicas do tecido pulmo-}

\section{nar}

Impedância $(Z)$ é o termo dado para um tipo especial de função de transferência, e no contexto das propriedades mecânicas dos pulmões, a impedância mecânica que realmente interessa é aquela que se dá entre o fluxo e a pressão. Normalmente, a impedância é obtida com o uso da TOF, na qual emprega-se variações de fluxo ou de pressão a freqüências determinadas e, posteriormente, investiga-se o conteúdo espectral resultante. Se o sinal de $\dot{V}(t)$ é aplicado na abertura das vias aéreas e o sinal de $P(t)$ correspondente é medido no mesmo local, estes dois sinais se relacionam da seguinte maneira:

$$
P(f)=Z(f) \dot{V}(f)
$$

onde $P(f)$ e $\dot{V}(f)$ são os resultados da transformada de Fourrier de $P(t)$ e $\dot{V}(t)$, respectivamente (Isto é, $P(f)$ e $\dot{V}(f)$ são a pressão e o fluxo no domínio da freqüência). Neste caso, $Z(f)$ é chamada de impedância de entrada (input impedance) porque ela relaciona duas grandezas mensuradas no mesmo local, na entrada dos pulmões.

Isto posto, de acordo com a equação 3.3 , a determinação da impedância deve ser realizada (i) medindo-se a $P(t)$ resultante da aplicação de um $\dot{V}(t)$, (ii) obtendo-se a transformada rápida de Fourrier dos dois sinais e, finalmente, (iii) executando-se o seguinte cálculo:

$$
Z(f)=\frac{P(f)}{\dot{V}(f)}
$$

Para determinar a impedância do sistema respiratório no domínio da freqüência, altera- 
se o sinal de fluxo para uma onda senoidal (de uma freqüência em particular), aplica-se este fluxo aos pulmões e executa-se a divisão proposta na equação 3.4 para a freqüência da senóide aplicada. Em vez de executar este procedimento para uma gama de freqüências, uma a uma, o que se realiza freqüentemente é aplicar um sinal de $\dot{V}(t)$ que contenha várias freqüências ao mesmo tempo. Como os pulmões "comportam-se" como um sistema linear dinâmico, o sinal resultante de $P(t)$ conterá componentes nas mesmas freqüências. Aplicando-se a transformada rápida de Fourrier aos sinais de $\dot{V}(t)$ e $P(t)$, obter-se-á $\dot{V}(f)$ e $P(f)$, respectivamente, que poderão ser utilizados na equação 3.4 para cada frequiência que eles contém.

Sistema linear dinâmico é aquele no qual o tempo exerce uma função e, por isso, os pulmões são considerados como tal. Quando um fluxo $\dot{V}(t)$ é aplicado aos pulmões, os efeitos resultantes na pressão $P(t)$ demoram um certo tempo para acontecer. Então, se o estímulo de entrada em um sistema linear dinâmico for uma onda senóide com uma freqüência f, a resposta (saída) do sistema também será uma onda senóide com a mesma freqüência. Entretanto, a onda senóide de saída será escalonada em amplitude por algum fator e atrasada em fase em alguma proporção. Matematicamente, a onda senóide de entrada é escrita desta forma: $x(t)=A_{i n} \operatorname{sen}\left(2 \pi f t+\phi_{i n}\right)$, onde $A_{i n}$ é a amplitude da entrada e $\phi_{i n}$ é a sua fase. Quando $x(t)$ é aplicada a um sistema linear dinâmico, a saída será: $x(t)=A_{\text {out }} \operatorname{sen}\left(2 \pi f t+\phi_{\text {out }}\right)$, onde o fator de escalonamento da amplitude é dado por $A=A_{\text {out }} / A_{\text {in }}$ e a mudança de fase é dada por: $\phi=\left(\phi_{\text {out }}-\phi_{\text {in }}\right)$.

Isto significa dizer que a forma da onda senoidal é preservada quando passa por um sistema deste tipo e esta característica de preservação da forma da onda não se aplica a nenhum outro tipo de estímulo de entrada, mas somente às senoidais. Este fato tem importante aplicação visto que sistemas lineares dinâmicos são completamente caracterizados pela forma na qual $A \mathrm{e}$ $\phi$ dependem da freqüência. Juntos, amplitude $(A(f))$ e fase $(\phi(f))$ constituem o que é conhecido como resposta em freqüência do sistema. ${ }^{35}$

Neste estudo, a TOF de múltiplas freqüências foi empregada para determinar a impedância do sistema respiratório na faixa entre 0,25 e 19,625 Hz. Um sinal composto contendo 19 ondas senóides, com duração de 8 segundos, foi aplicado na abertura das vias aéreas durante pausas na ventilação mecânica regular, como ilustrado na figura 3.4 . 


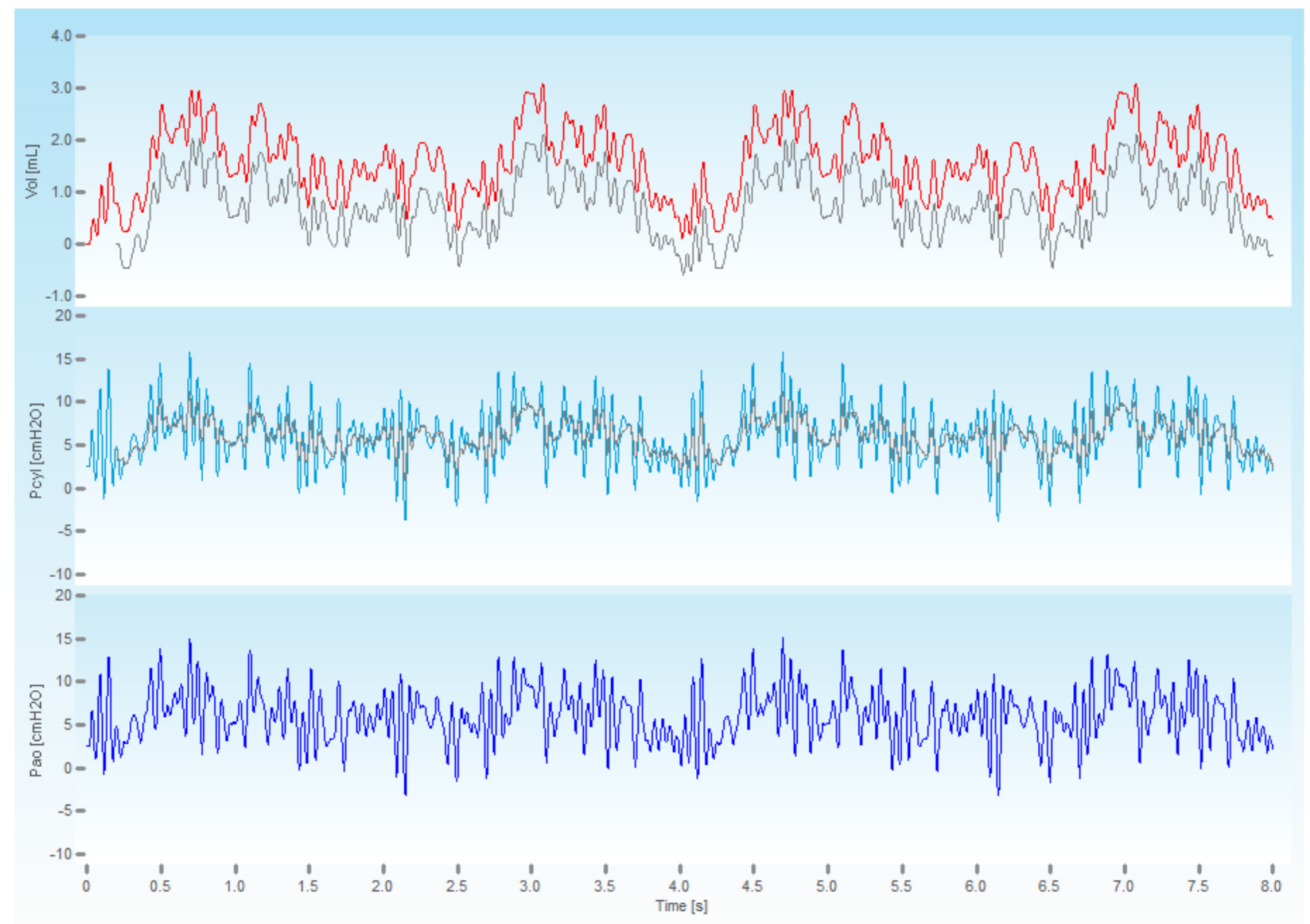

Figura 3.4: Técnica de oscilação forçada de múltiplas freqüências realizada pelo FlexiVent FX aplicada na abertura das vias aéreas para determinação das impedâncias do sistema respiratório e do tecido pulmonar (com aplicação do modelo de fase constante). De cima para baixo: traçados de volume $(V)$, pressão no cilindro do ventilador mecânico $\left(P_{c y l}\right)$ e pressão na abertura das vias aéreas $\left(P_{a o}\right)$. No traçado de volume, a linha vermelha representa o volume no cilindro do ventilador mecânico e a linha cinza o volume entregue aos pulmões de um determinado rato.

Em qualquer freqüência, a impedância é um número complexo que possui uma parte real e outra imaginária, e neste contexto, a utilização de números complexos é um artifício matemático para manter o controle das ondas senóides e cossenóides, independentemente. Quando uma onda senóide entra num sistema linear dinâmico, parte da onda de saída (a parte senóide da onda) está em fase, enquanto que a outra parte (a cossenóide) está 90 graus (ou $\pi / 2$ radianos) fora de fase em relação à onda de entrada. A parte real da $Z_{r s}$ é a resistência do sistema respiratório e a imaginária é a reatância $(X)$. 
Com o intuito de dividir a impedância do sistema respiratório nos componentes mecânicos das vias aéreas centrais e do parênquima pulmonar, os dados do espectro da $Z_{r s}$ foram ajustados ao modelo de fase constante descrito por Hantos: ${ }^{36}$

$$
Z(f)=R_{N}+i \omega I+\frac{G-i H}{\omega^{\alpha}}
$$

onde

$$
\alpha=\frac{2}{\pi} \tan ^{-1} \frac{H}{G}
$$

$R_{N}$ é a resistência Newtoniana e $I$ representa a inertância do gás nas vias aéreas centrais. Somadas, $R_{N}$ e $I$ representam a impedância das vias aéreas. G é comumente chamado de amortecimento tecidual e $H$ caracteriza o armazenamento de energia elástica no tecido pulmonar. Portanto, $G$ e $H$ são responsáveis pela impedância do tecido pulmonar. $G$ representa o componente dissipativo, está relacionado com a resistência tecidual e reflete a dissipação de energia nos alvéolos, enquanto que $H$ está intimamente relacionada à elastância do tecido pulmonar e reflete a conservação de energia nos alvéolos.

É importante ressaltar que $G$ e $H$ não são o mesmo que resistência e elastância do tecido pulmonar porque não possuem as mesmas unidades de medida. Curiosamente, $G$ e $H$ têm a característica de possuírem unidades de medida determinadas pelos seus valores relativos. O exame da equação 3.5 mostra que quando $Z(f)$ é expressa em unidades de $\mathrm{cmH}_{2}$ O.s.L $\mathrm{L}^{-1}$, $G$ e $H$ possuem unidades de $\mathrm{cmH}_{2} \mathrm{O} \cdot \mathrm{s}^{1-\alpha} \cdot \mathrm{L}^{-1}$. Estas unidades modificam-se com o valor de $\alpha$ que, por sua vez, é determinado pela razão $G / H$ (equação 3.6). Uma forma de contornar esta questão de unidades de medidas variáveis é normalizar o termo da impedância tecidual da equação 3.5 pela freqüência de referência $\omega_{0}:{ }^{37}$

$$
Z(\omega)=R_{N}+i(\omega) I+\frac{G-i H}{\left(\omega / \omega_{0}\right)^{\alpha}}
$$

Com $\omega_{0}=0$, os valores de $G$ e $H$ permanecem inalterados, ainda que eles tenham, agora, as mesmas unidades de medida de $Z$.

De acordo com a equação 3.5, os parâmetros $R_{N}, I, G$ e $H$ relacionam-se linearmente com $Z(f)$ e, sendo assim, o ajuste dos dados reais de impedância ao modelo de fase constante 
seria simplesmente realizado utilizando-se a regressão linear múltipla (tal como descrito para o modelo linear unicompartimental - item 3.4), se não fosse a presença do coeficiente $\alpha$ no denominador do último termo da equação.

Para contornar este problema, é preciso encontrar uma boa estimativa de $\alpha$ que ajuste os dados ao modelo de fase constante. Para tal, Bates ${ }^{35}$ propõe um esquema iterativo onde, primeiramente, considera-se $\alpha=1$ e utiliza-se a regressão linear múltipla para obter os valores de $R_{N}, I, G$ e $H$. O próximo passo, então, é calcular a nova estimativa de $\alpha$ utilizando-se os valores de $G$ e $H$ via equação 3.6 e, novamente, realiza-se a regressão linear múltipla com o novo valor de $\alpha$. Todos estes passos podem ser realizados quantas vezes forem necessárias e, de acordo com o autor, os valores dos parâmetros obtidos convergem após quatro ou cinco iterações.

Tal como descrito no item 3.4, os valores de impedância do sistema respiratório e do tecido pulmonar apresentados na seção de resultados são somente aqueles obtidos a partir de regressões que apresentaram $\mathrm{COD} \geq 95 \%$.

\subsection{Análise morfométrica do tecido pulmonar}

Ao término da avaliação das propriedades mecânicas do sistema respiratório e dos pulmões, a caixa torácica dos animais foi aberta por esternotomia mediana e o bloco coraçãopulmões retirado em bloco. O pulmão esquerdo foi insuflado com $5 \mathrm{~mL}$ de solução de formol tamponado a 10\% e após a ligadura do brônquio fonte, foi conservado em solução de formol de mesma concentração. Em seguida, o tecido pulmonar foi processado para cortes histológicos com parafina (com 3 micrômetros de espessura) e realizada coloração com hematoxilina-eosina (HE) e picrosírius.

O percentual de fibras colágenas no parênquima pulmonar foi calculado com a utilização do software de análise de imagens ImageJ. Com uma câmera digital (Nikon D7000, Tailândia) acoplada ao microscópio óptico, cinco campos de cada lâmina (escolhidos de forma aleatória) corada com picrosírius foram fotografados no aumento de 400x. Uma primeira imagem foi obtida e, sob luz polarizada, o mesmo campo foi fotografado novamente (Figuras 3.5 A e B). A 
primeira imagem foi utilizada para calcular o percentual do campo ocupado pelo parênquima pulmonar (área em vermelho da Figura 3.5 C), excluindo-se, portanto, o percentual do campo ocupado pelos alvéolos, e a segunda para determinar o percentual do campo ocupado pelas fibras colágenas (área em vermelho da Figura 3.5D). Portanto, o percentual de fibras colágenas no parênquima pulmonar foi calculado da seguinte forma:

$$
\% \text { Fibras colágenas no parênquima }=\left(\frac{\% \text { fibras colágenas }}{\% \text { parênquima pulmonar }}\right) \times 100
$$

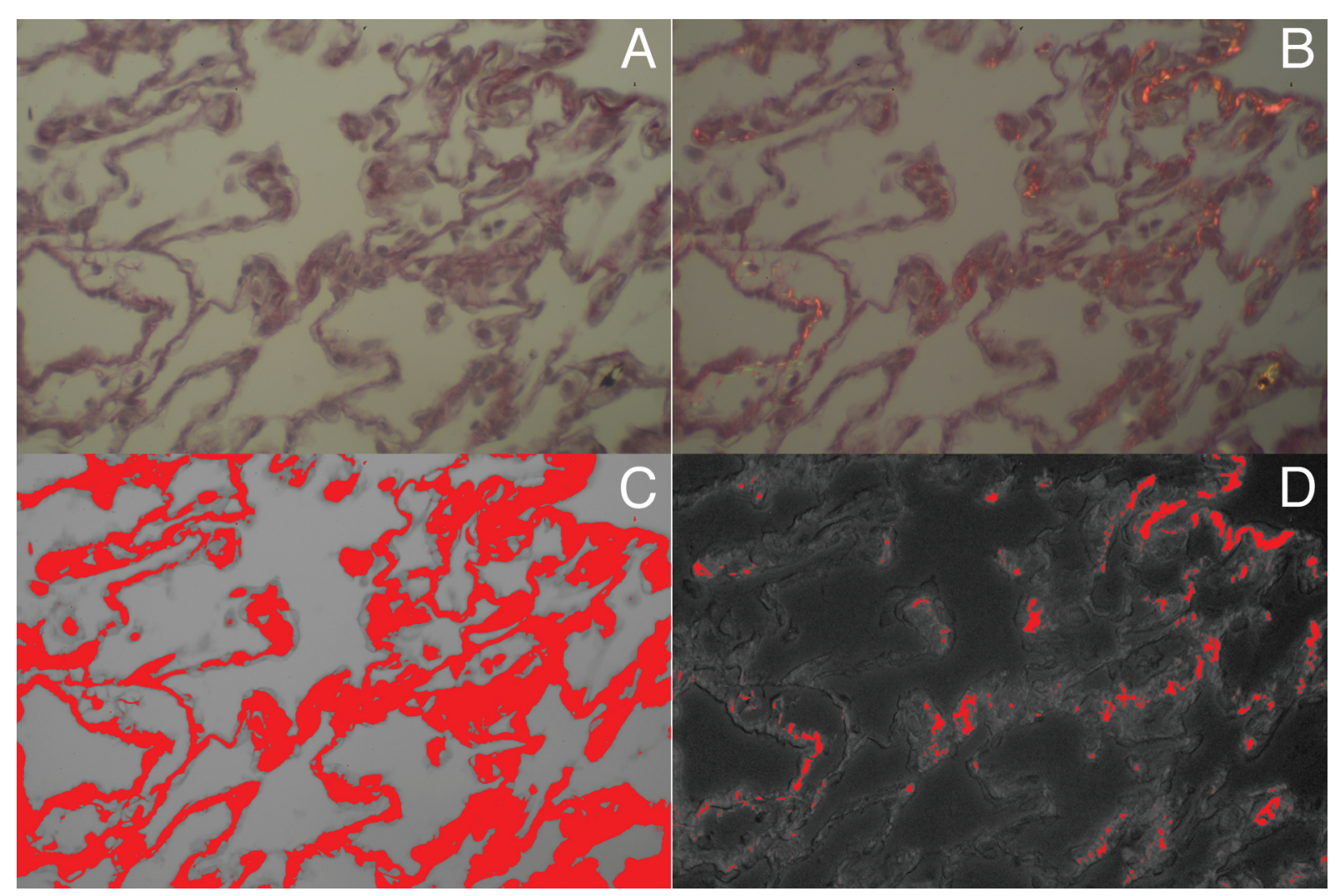

Figura 3.5: A) fotomicrografia do parênquima pulmonar corado com hematoxilina-eosina. B) fotomicrografia do parênquima pulmonar corado com picrosírius visualizado sob luz polarizada; sob esta luz, as fibras colágenas coram-se em laranja. C) identificação e quantificação do parênquima pulmonar (marcado em vermelho) pelo software ImageJ. D) identificação e quantificação das fibras colágenas (marcadas em vermelho) no parênquima pulmonar pelo software ImageJ. 
A análise morfométrica das demais variáveis pulmonares foi realizada como previamente descrita por Gundersen, ${ }^{38}$ com a utilização de um sistema teste coerente e de referência composto por 100 pontos e 50 linhas (de comprimento conhecido) acoplado à uma das oculares do microscópio óptico (Axioplan; Zeiss, Oberkochen, Alemanha). De cada lâmina, dez campos não coincidentes, escolhidos de forma aleatória, foram utilizados para a realização de tal análise. O sistema teste está ilustrado na Figura 3.6.

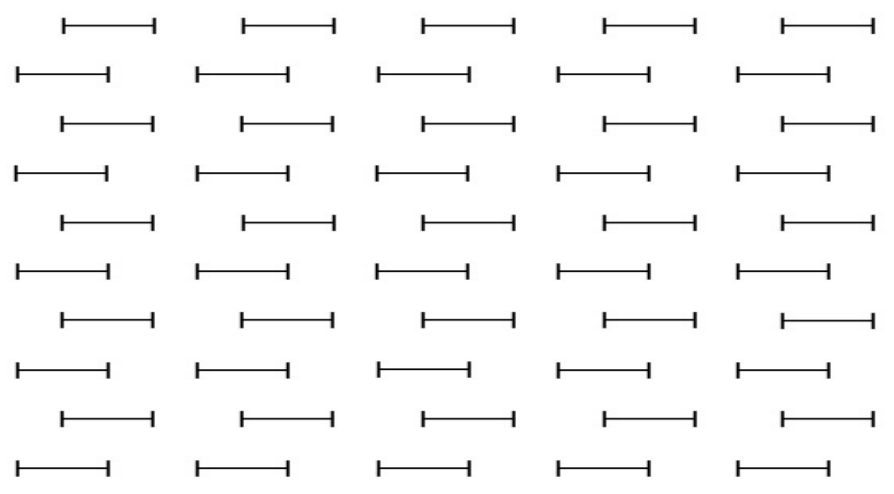

Figura 3.6: Sistema teste coerente e de referência composto por 100 pontos e 50 linhas utilizado para a quantificação do percentual de fibras colágenas nas vias aéreas e determinação do índice de edema alveolar.

Com a técnica de contagem de pontos ${ }^{38}$ foram mensurados: (1) a proporção de fibras colágenas na vasculatura pulmonar, e (2) o índice de edema alveolar (IEA). O cálculo da proporção de fibras colágenas na vasculatura pulmonar foi realizada com aumento de 1000x no microscópio óptico, nas lâminas coradas com picrosírius e sob luz polarizada. Foram escolhidas, de maneira aleatória, 5 artérias pulmonares com área de até $10.000 \mu \mathrm{m}^{2}$, e foi contado o número de pontos do retículo que incidiam sobre os fibras colágenas dividido pela quantidade de pontos que incidiam sobre a área da artéria, como descrito na equação abaixo:

$\%$ Fibras colágenas na artéria $=\frac{\mathrm{N}^{\mathrm{o}} \text { de pontos que incidem sobre as fibras colágenas }}{\mathrm{N}^{\mathrm{o}} \text { de pontos que incidem sobre a área arterial }}$

O índice de edema alveolar foi calculado com aumento de 400x no microscópio óptico, utilizando-se as lâminas coradas com hematoxilina-eosina. De maneira aleatória, foram escolhidos 10 campos de cada lâmina e contado o número de pontos que incidiam sobre a área de edema intra-alveolar, dividido pela quantidade de pontos que incidiam sobre o interior dos 
alvéolos, de acordo com a equação abaixo:

$$
\mathrm{IEA}=\frac{\mathrm{N}^{\mathrm{o}} \text { de pontos que incidem sobre a área de edema intraalveolar }}{\mathrm{N}^{\mathrm{o}} \text { de pontos que incidem sobre o interior dos alvéolos }}
$$

\subsection{Aquisição dos sinais}

Todas as perturbações ao sistema respiratório descritas nos itens 3.3, 3.4 e 3.5 foram realizadas pelo FlexiVent FX (Scireq, Montréal, Canadá) em pausas da ventilação mecânica regular, sob o comando do software FlexiWare 7.5 (Scireq, Montréal, Canadá). Além disso, este software foi responsável pela coleta dos sinais dos transdutores de pressão e de fluxo provenientes do próprio ventilador mecânico e pelos cálculos acima descritos.

\subsection{Análise estatística}

A normalidade da distribuição dos dados dos pesos dos animais, das propriedades mecânicas do sistema respiratório e dos pulmões, e da morfologia pulmonar foi examinada com a utilização do teste de Shapiro-Wilk.

A hipótese nula de que não havia diferença dos pesos dos animais dos oito grupos estudados no momento no qual foram administradas as soluções salina, e ou de dexametasona e ou de docetaxel (nas diferentes doses) foi testada com a utilização da análise de variância de um fator (ANOVA one-way) e a homogenidade das variâncias foi verificada com o teste de Levene. No caso de rejeição desta hipótese nula, o pós-teste de Tukey foi empregado para comparação emparelhada dos grupos.

A ANOVA com dois fatores (ANOVA two-way) foi utilizada para testar as hipóteses nulas de que os pesos dos animais, as propriedades mecânicas do sistema respiratório e dos pulmões, bem como a morfologia do tecido pulmonar não seriam modificados pelos efeitos:

1. do docetaxel anidro;

2. da dexametasona; 
3. da interação entre docetaxel anidro $x$ dexametasona.

A homogeneidade das variâncias foi verificada com o teste de Levene e a análise dos resíduos foi conduzida para testar as suposições da ANOVA com dois fatores. Todas as vezes nas quais as variáveis estudadas foram modificadas pelo efeito de um fator (docetaxel anidro ou dexametasona e não pela sua interação), foi realizada a análise do efeito principal (main effects) com comparações emparelhadas conduzidas com o ajuste de Bonferroni.

Nos casos onde houve efeito da interação docetaxel anidro $x$ dexametasona nas variáveis estudadas, foi conduzida a análise do efeito principal simples (simple main effects) para as comparações emparelhadas com ajuste de Bonferroni para estas múltiplas comparações.

Todas as análises estatísticas foram realizadas com o programa Statistical Package for Social Science (IBM SPSS Statistics para Mac OSX, Versão 20.0. Armonk, NY, IBM Corp.). O nível de significância estabelecido para todas as análises foi de $5 \%$ e os resultados estão expressos na forma de média \pm desvio-padrão, exceto se indicado de outra forma. 
${ }_{\text {Capítulo }}$

\section{Resultados}

\subsection{Peso dos animais}

No momento em que foram administradas as soluções salina, e ou de dexametasona e ou de docetaxel anidro nas diferentes doses, não houve diferença no peso dos animais dos oito grupos estudados, $F(7,52)=1,04, p=0,41$, como mostrado na figura 4.1 .

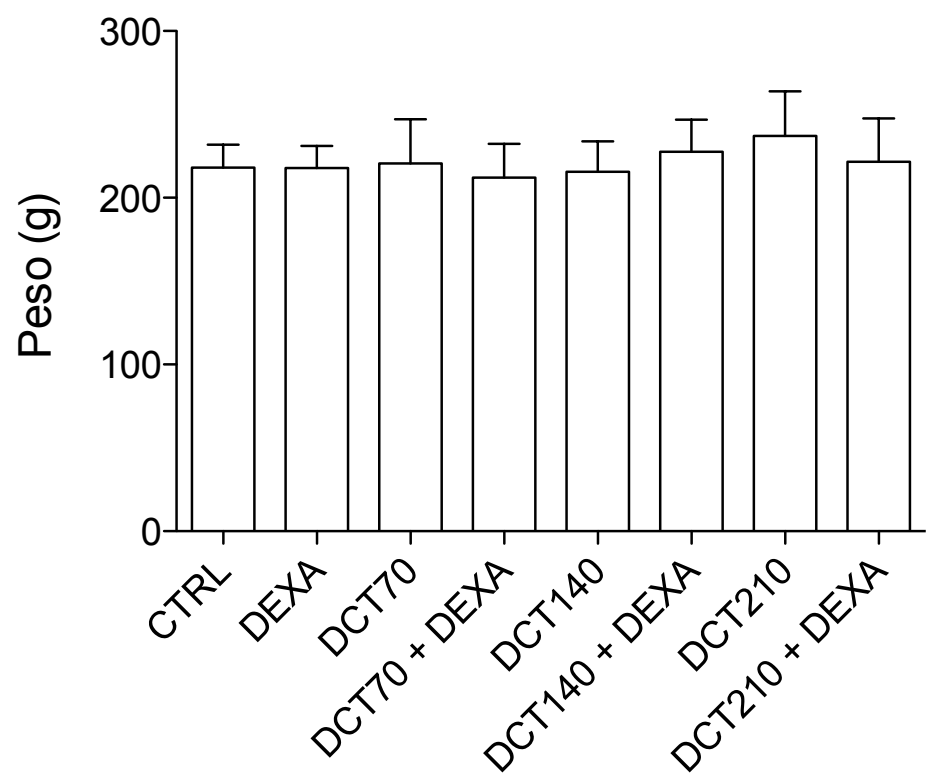

Figura 4.1: peso dos animais dois oito grupos estudados no momento em que foram administradas as soluções salina, e ou de docetaxel anidro nas diferentes doses e ou de dexametasona. As barras representam a média \pm desvio-padrão.

Contudo, o ganho percentual médio de peso após 4 semanas da administração dos 
medicamentos foi diferente entre os grupos. Esta diferença não se deveu ao efeito da interação docetaxel anidro $x$ dexametasona, $F(3,52)=1,58, p=0,21, \eta^{2}$ parcial $=0,084$. A análise do efeito principal da administração destes dois medicamentos demonstrou efeito significativo para ambos: docetaxel anidro, $F(3,52)=16,51, p<0,001, \eta^{2}$ parcial $=0,488$; dexametasona, $F(3,52)=7,61, p=0,008, \eta^{2}$ parcial $=0,128$.

Considerando-se o efeito principal da administração do docetaxel anidro, o ganho percentual médio de peso dos animais que não receberam este quimioterápico foi maior que daqueles que receberam a 70 mg.m ${ }^{-2}, 12,5 \%$ (IC 95\%, 4,1 a 20,9), $p=0,001 ; 140$ mg.m ${ }^{-2}, 13,9 \%$ (IC 95\%, 5,5 a 22,4), $p<0,001$; e $210 \mathrm{mg} \cdot \mathrm{m}^{-2}, 22,5 \%$ (IC 95\%, 13,6 a 31,5), $p<0,001$. Ainda assim, houve diferença de 10,1\% no ganho de peso dos animais nos quais o docetaxel anidro foi administrado na dose de $70 \mathrm{mg} \cdot \mathrm{m}^{-2}$ quando comparado aos que receberam o quimioterápico na dose de 210 mg.m ${ }^{-2}$ (IC 95\%, 1,2 a 18,9), $p=0,01$. Por outro lado, o ganho percentual médio de peso foi similar entre os animais que receberam docetaxel anidro nas doses de 70 e 140 mg.m ${ }^{-2}, 1,5 \%$ (IC 95\%, -6,8 a 9,8), p=1; e 140 e 210 mg.m ${ }^{-2}, 8,6 \%$ (IC 95\%, -0,1 a 17,5), $p=0,055$ (Figura 4.2).

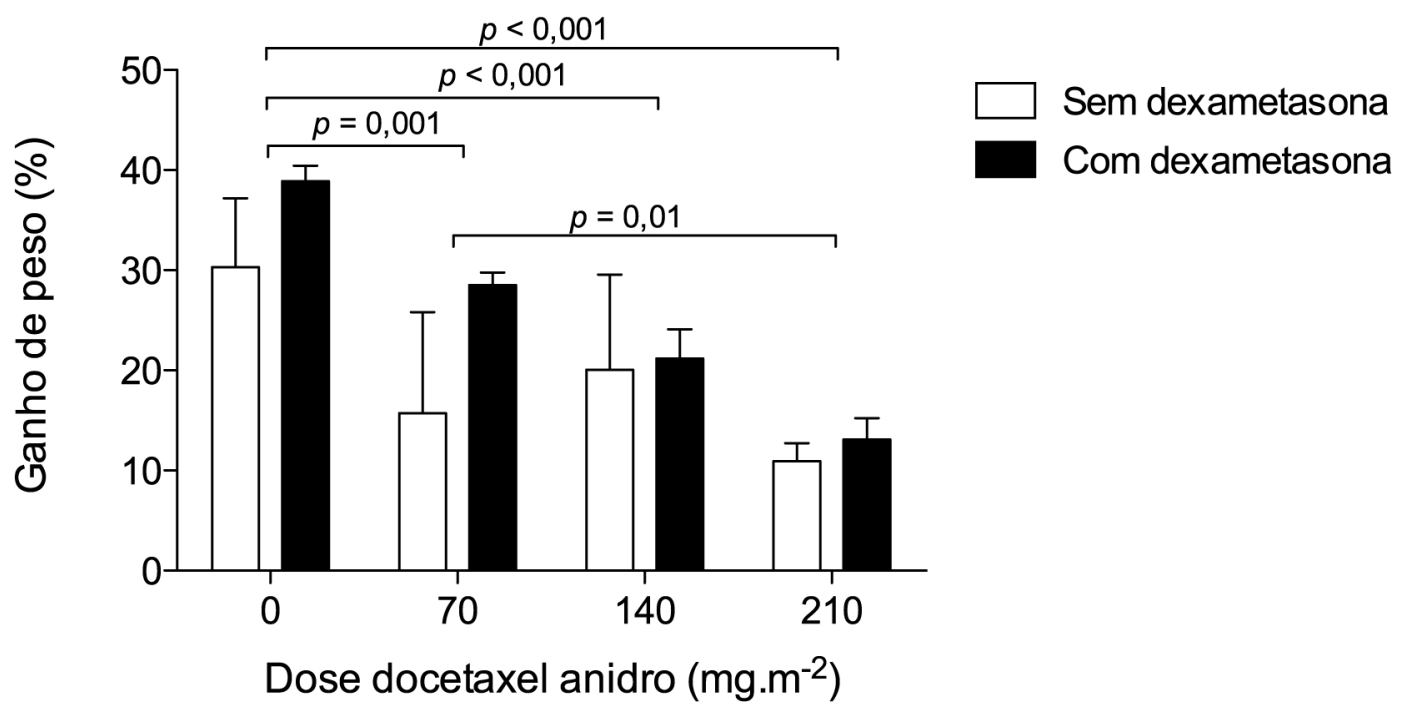

Figura 4.2: Peso dos animais dois oito grupos estudados no momento em que foram administradas as soluções salina, e ou de docetaxel nas diferentes doses e ou de dexametasona. As barras representam a média \pm desvio-padrão.

A análise do efeito principal da administração da dexametasona demonstrou que os animais que a receberam ganharam, em média, 6,15\% mais peso quando comparado aos que não receberam (IC95\%, 1,7 a 10,6), $p=0,008$ (Figura 4.3). 


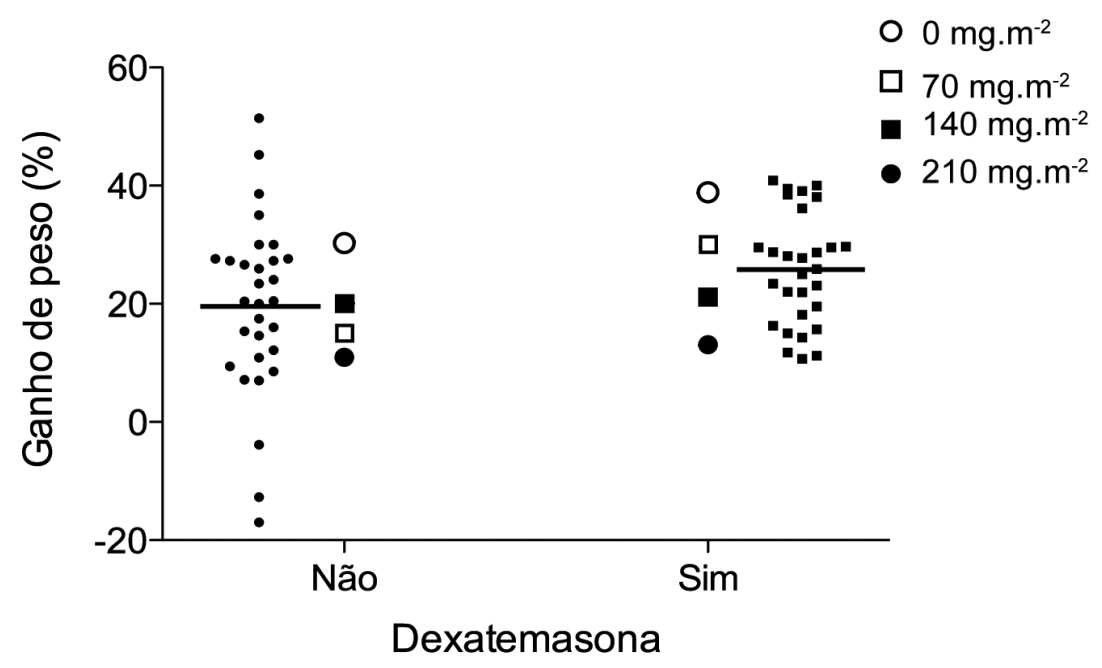

Figura 4.3: Efeito principal da administração da dexametasona no ganho percentual médio de peso após 4 semanas da sua administração. Os símbolos representam a média; nos diagramas de dispersão, as barras horizontais representam a média.

\subsection{Resistência e elastância do sistema respiratório}

A resistência do sistema respiratório não se alterou sob a influência da administração do docetaxel anidro, $F(3,52)=1,83, p=0,152, \eta^{2}$ parcial $=0,091$; nem da dexametasona, $F(3$, $52)=2,56, p=0,115, \eta^{2}$ parcial $=0,045$; nem da interação docetaxel anidro $x$ dexametasona, $F(3,52)=0,59, p=0,624, \eta^{2}$ parcial $=0,031$, como mostrado na tabela 4.1 .

Tabela 4.1: Resistência do sistema respiratório dos animais dos 8 grupos estudados. Efeitos principais do docetaxel anidro, da dexametasonsa e da sua interação.

\begin{tabular}{|c|c|c|c|c|c|c|c|}
\hline \multirow[b]{4}{*}{ Dexa } & \multicolumn{4}{|c|}{$R_{r s}\left(\mathrm{cmH}_{2}\right.$ O.mL.s $\left.{ }^{-1}\right)$} & \multirow{2}{*}{\multicolumn{2}{|c|}{ Efeito principal }} & \multirow{4}{*}{$\begin{array}{c}\text { Interação } \\
\text { DCTxDexa } \\
p \text {-valor }\end{array}$} \\
\hline & \multirow{2}{*}{\multicolumn{4}{|c|}{$\begin{array}{c}\text { Dose DCT } \\
\left(\mathbf{m g} \cdot \mathbf{m}^{-2}\right)\end{array}$}} & & & \\
\hline & & & & & \multirow{2}{*}{$\begin{array}{c}\text { DCT } \\
p \text {-valor }\end{array}$} & \multirow{2}{*}{$\begin{array}{c}\text { Dexa } \\
p \text {-valor }\end{array}$} & \\
\hline & 0 & 70 & 140 & 210 & & & \\
\hline Não & $0,09 \pm 0,02$ & $0,09 \pm 0,01$ & $0,10 \pm 0,01$ & $0,10 \pm 0,02$ & & & \\
\hline Sim & $0,08 \pm 0,01$ & $0,10 \pm 0,01$ & $0,09 \pm 0,01$ & $0,09 \pm 0,01$ & 0,1 & 0, & \\
\hline
\end{tabular}

$\overline{\mathrm{Rrs}}=$ resistência do sistema respiratório; DCT $=$ docetaxel anidro; Dexa $=$ dexametasona. Os valores representam a média \pm desvio-padrão.

Ao contrário do que foi observado na resistência, a $E_{r s}$ se elevou com a administração do docetaxel anidro, $F(3,52)=2,91, p=0,043, \eta^{2}$ parcial $=0,137$. Quando comparado aos animais para quem não foi administrado o quimioterápico, a elastância do sistema respiratório dos animais que receberam $210 \mathrm{mg} \cdot \mathrm{m}^{-2}$ de docetaxel se elevou, em média, $0,34 \mathrm{cmH}_{2} \mathrm{O} \cdot \mathrm{mL}^{-1}$ 
(IC 95\%, 0,02 a 0,67), $p=0,028$. Para as demais doses de docetaxel anidro, não houve diferença significativa na $E_{r s}$, e os resultados das comparações emparelhadas, foram: 0 e 70 mg.m ${ }^{-2}, 0,21$ $\mathrm{cmH}_{2} \mathrm{O} \cdot \mathrm{mL}^{-1}$ (IC 95\%, -0,5 a 0,11), $p=0,493 ; 0$ e $140 \mathrm{mg} \cdot \mathrm{m}^{-2}, 0,23 \mathrm{cmH}_{2} \mathrm{O} \cdot \mathrm{mL}^{-1}$ (IC 95\%, $0,09$ a 0,56$), p=0,342 ; 70$ e $140 \mathrm{mg} \cdot \mathrm{m}^{-2}, 0,02 \mathrm{cmH}_{2} \mathrm{O} \cdot \mathrm{mL}^{-1}$ (IC 95\%, -0,34 a 0,29), $p=1$; 70 e 210 mg.m ${ }^{-2}, 0,14 \mathrm{cmH}_{2} \mathrm{O} \cdot \mathrm{mL}^{-1}$ (IC 95\%, -0,45 a 0,17), p=1; 140 e $210 \mathrm{mg} \cdot \mathrm{m}^{-2}, 0,11$ $\mathrm{cmH}_{2} \mathrm{O} \cdot \mathrm{mL}^{-1}$ (IC 95\%, -0,43 a 0,21), $p=1$. Estes resultados estão mostrados na figura 4.4 .

Em contrapartida, a $E_{r s}$ não foi influenciada pela dexametasona, $F(3,52)=3,44, p=$ 0,069, $\eta^{2}$ parcial $=0,059$ e nem pela interação docetaxel anidro $x$ dexametasona, $F(3,52)=$ $0,42, p=0,739, \eta^{2}$ parcial $=0,022$.

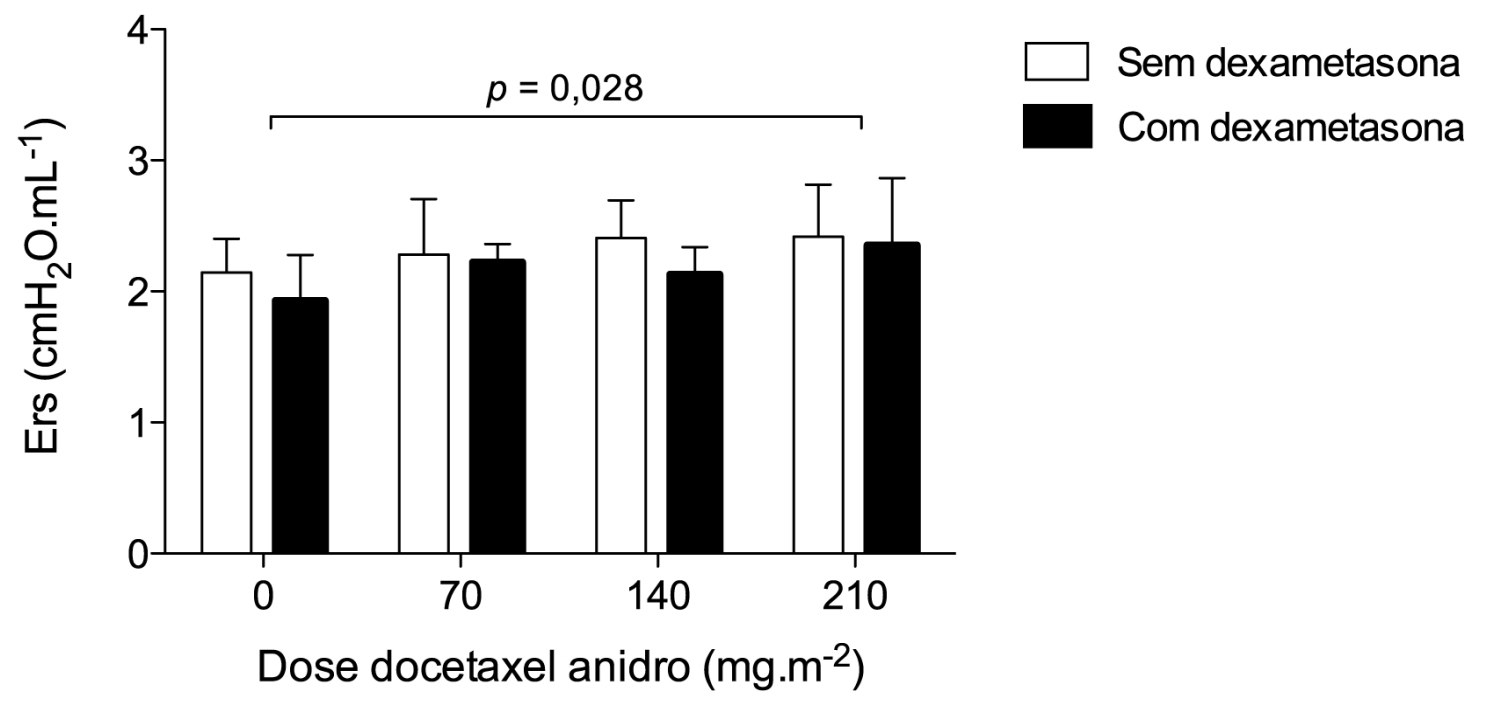

Figura 4.4: Efeito principal da administração do docetaxel anidro na elastância do sistema respiratório após 4 semanas da sua administração. As barras representam a média \pm desviopadrão.

\subsection{Impedância do sistema respiratório e propriedades mecânicas do tecido pulmonar}

O espectro da impedância do sistema respiratório na faixa entre 0,25 e 19,625 Hz juntamente com o ajuste do modelo de fase constante de todos os grupos estudados estão mostrados na figura 4.5 . 

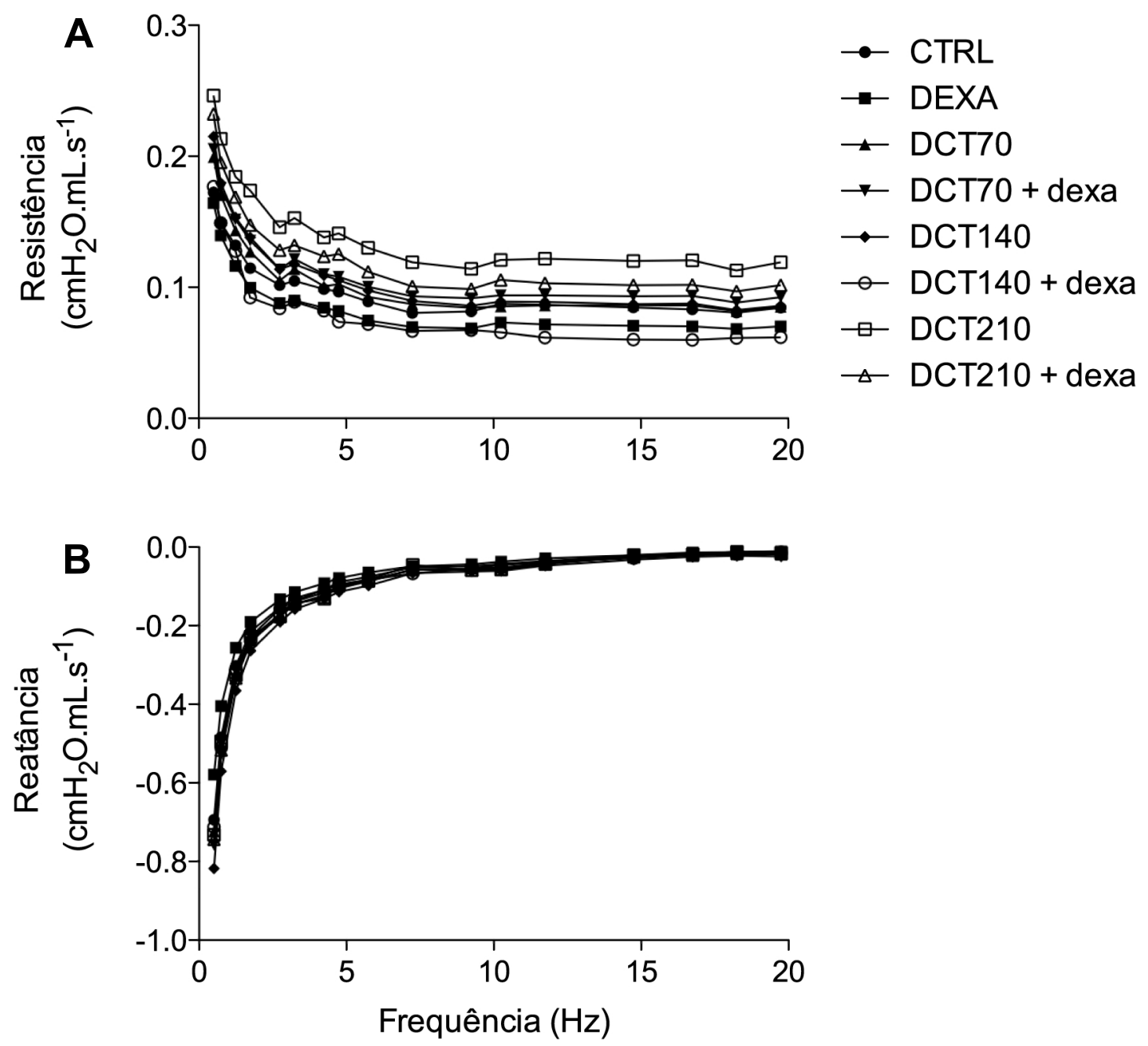

Figura 4.5: espectro da impedância do sistema respiratório na faixa entre 0,25 e 19,625 Hz juntamente com o ajuste do modelo de fase constante de todos os grupos estudados. A) Componente resistivo; B) Componente imaginário - reatância.

A resistência Newtoniana não se alterou com a aplicação do docetaxel anidro, $F(3,52)$ $=0,108, p=0,955, \eta^{2}$ parcial $=0,006$; nem com a administração da dexametasona, $F(3,52)$ $=0,148, p=0,702, \eta^{2}$ parcial $=0,003$; e nem pela sua interação: $F(3,52)=0,076, p=0,973$, $\eta^{2}$ parcial $=0,004$, como ilustrado na figura 4.6 .

Por outro lado, a dissipação de energia no tecido pulmonar foi diferente entre os grupos, e se elevou significativamente com o aumento crescente das doses de docetaxel anidro, $F(3,52)$ $=6,96, p<0,001, \eta^{2}$ parcial $=0,275$, não sofrendo efeito da aplicação da dexametasona, $F(3$, $52)=0,000, p=0,984, \eta^{2}$ parcial $=0,000$, e nem da interação entre estes dois medicamentos, $F(3,52)=0,418, p=0,741, \eta^{2}$ parcial $=0,022$. 


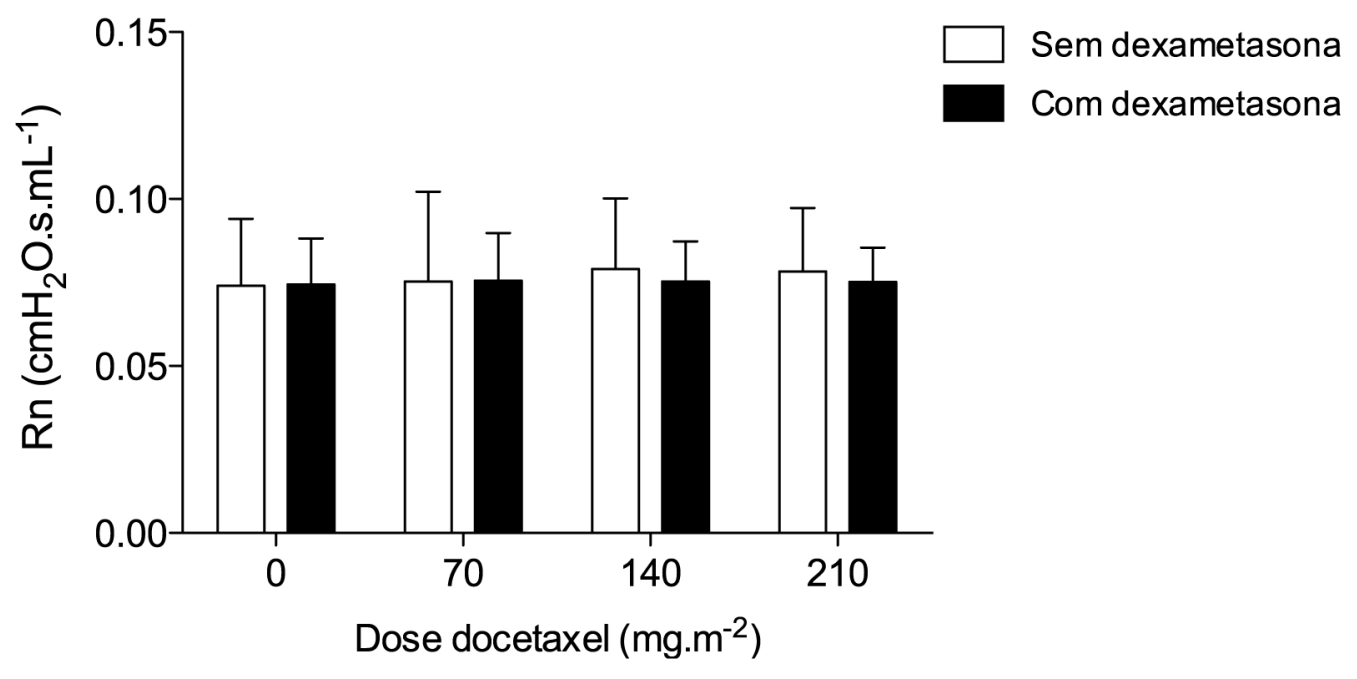

Figura 4.6: Efeito principal da administração do docetaxel anidro na resistência Newtoniana $\left(R_{N}\right)$ após 4 semanas da sua administração. As barras representam a média \pm desvio-padrão.

Analisando-se o efeito principal da administração do docetaxel anidro, e em comparação com os animais que não receberam o quimioterápico, a dissipação de energia no tecido pulmonar aumentou, em média, 0,076 $\mathrm{cmH}_{2} \mathrm{O} \cdot \mathrm{mL}^{-1}$ (IC 95\%, 0,025 a 0,127), $p=0,001$ naqueles que receberam 70 mg.m ${ }^{-2} ; 0,073 \mathrm{cmH}_{2} \mathrm{O} \cdot \mathrm{mL}^{-1}$ (IC 95\%, 0,020 a 0,125), $p=0,003$ nos que receberam o quimioterápico na dose de $140 \mathrm{mg} \cdot \mathrm{m}^{-2}$; e $0,063 \mathrm{cmH}_{2} \mathrm{O} \cdot \mathrm{mL}^{-1}$ (IC 95\%, 0,012 a 0,115), $p=$ 0,009 nos que receberam o quimioterápico na dose de $210 \mathrm{mg} \cdot \mathrm{m}^{-2}$. Os resultados das demais comparações emparelhadas, foram: $70 x 140 \mathrm{mg} \cdot \mathrm{m}^{-2}$ : 0,003 $\mathrm{cmH}_{2} \mathrm{O} \cdot \mathrm{mL}^{-1}$ (IC 95\%, -0,047 a 0,54), $p=0,998 ; 70 x 210$ mg.m ${ }^{-2}: 0,012 \mathrm{cmH}_{2} \mathrm{O} \cdot \mathrm{mL}^{-1}$ (IC 95\%, -0,037 a 0,062), $p=0,907$; $140 x 210$ mg.m ${ }^{-2}: 0,009 \mathrm{cmH}_{2} \mathrm{O} \cdot \mathrm{mL}^{-1}$ (IC 95\%, -0,042 a 0,06), $p=0,964$. (Figura 4.7). 


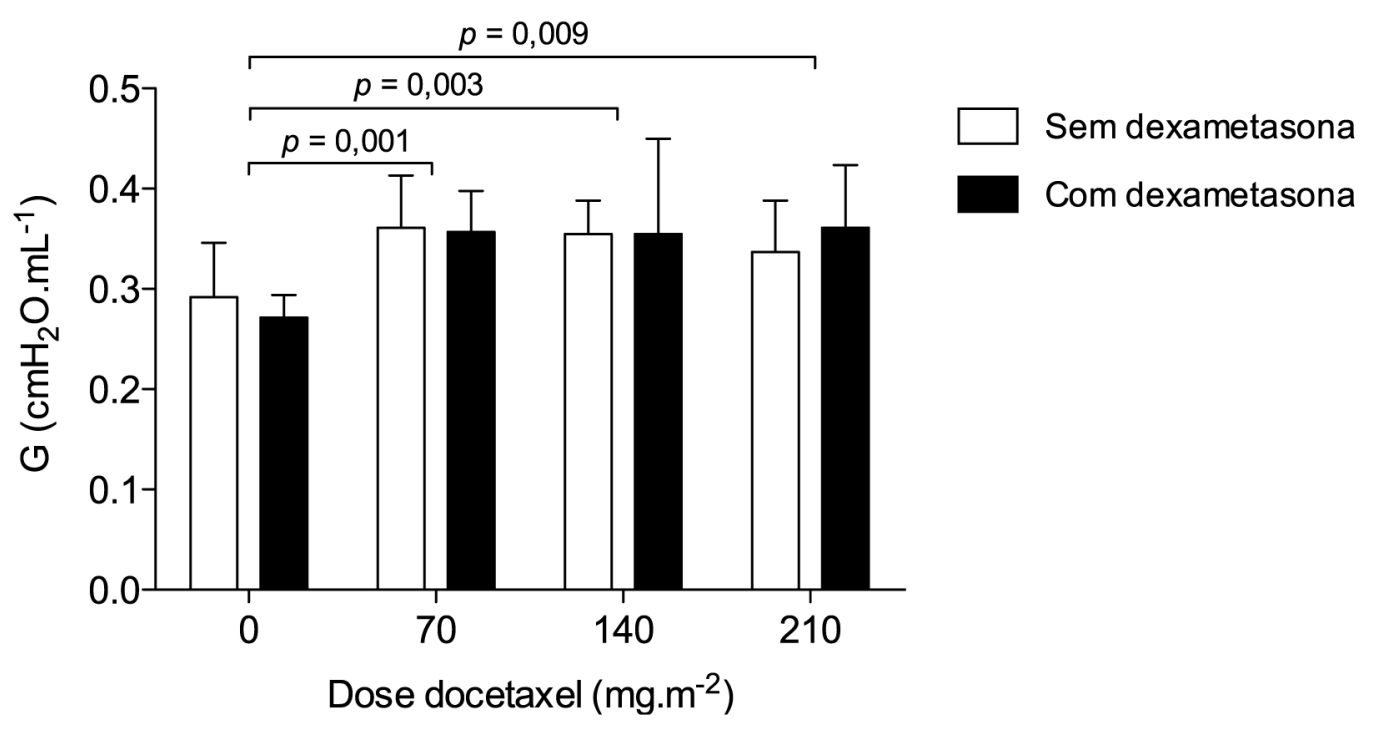

Figura 4.7: Efeito principal da administração do docetaxel anidro na dissipação de energia no tecido pulmonar $(G)$ após 4 semanas da sua administração. As barras representam a média \pm desvio-padrão.

Tal como o ocorrido com a variável $G$, a conservação de energia no tecido pulmonar se elevou sob o efeito da administração do docetaxel anidro, $F(3,52)=3,41, p=0,024, \eta^{2}$ parcial $=0,157$, não sofrendo efeito da aplicação da dexametasona, $F(3,52)=0,004, p=0,951$, $\eta^{2}$ parcial $=0,000$, e nem da interação docetaxel anidro $x$ dexametasona, $F(3,52)=0,218$, $p=0,884, \eta^{2}$ parcial $=0,012$.

Como ilustrado na figura 4.8, e considerando-se o efeito principal da aplicação do docetaxel anidro, a conservação de energia no tecido pulmonar foi, em média, 0,386 $\mathrm{cmH}_{2} \mathrm{O} \cdot \mathrm{mL}^{-1}$ maior nos animais que receberam o quimioterápico na dose de $210 \mathrm{mg} \cdot \mathrm{m}^{-2}$ quando comparado aos que não receberam (IC 95\%, 0,036 a 0,736), $p=0,023$. Para os demais grupos, não houve diferenças significativas e os resultados das comparações emparelhadas, foram: $0 x 70 \mathrm{mg} \cdot \mathrm{m}^{-2}$ : $-0,127 \mathrm{cmH}_{2} \mathrm{O} \cdot \mathrm{mL}^{-1}$ (IC 95\%, -0,467 a 0,213), $p=1 ; 0 x 140 \mathrm{mg} \cdot \mathrm{m}^{-2}$ : $-0,258 \mathrm{cmH}_{2} \mathrm{O} \cdot \mathrm{mL}^{-1}$ (IC 95\%, -0,608 a 0,092), $p=0,293 ; 70 x 140$ mg.m ${ }^{-2}$ : -0,131 $\mathrm{cmH}_{2} \mathrm{O} \cdot \mathrm{mL}^{-1}$ (IC 95\%, -0,471 a 0,209), $p=1 ; 70 x 210$ mg.m ${ }^{-2}:-0,259 \mathrm{cmH}_{2} \mathrm{O} \cdot \mathrm{mL}^{-1}$ (IC 95\%, -0,598 a 0,081), $p=0,249 ; 140$ $x 210$ mg.m ${ }^{-2}:-0,128 \mathrm{cmH}_{2} \mathrm{O} \cdot \mathrm{mL}^{-1}$ (IC 95\%, -0,478 a 0,222), $p=1$. 


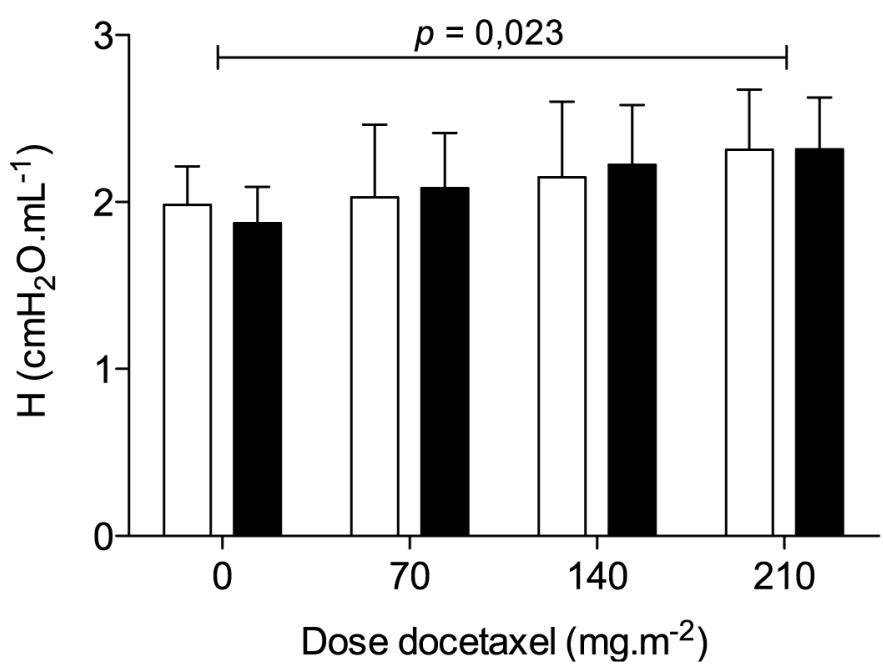

$\square$ Sem dexametasona

Com dexametasona

Figura 4.8: Efeito principal da administração do docetaxel anidro na conservação de energia no tecido pulmonar $(H)$ após 4 semanas da sua administração. As barras representam a média \pm desvio-padrão.

\subsection{Morfologia do tecido pulmonar}

Após 4 semanas da administração do docetaxel anidro e ou da dexametasona, o percentual de fibras colágenas no parênquima pulmonar foi diferente entre os grupos estudados, e este fenômeno se deveu ao efeito principal da aplicação do docetaxel anidro, $F(3,52)=123,3$, $p<0,001, \eta^{2}$ parcial $=0,896$. Esta variável não sofreu efeito significativo da administração da dexametasona, $F(3,52)=0,215, p=0,645, \eta^{2}$ parcial $=0,005$, e nem da interação entre o quimioterápico e o corticoide, $F(3,52)=1,351, p=0,271, \eta^{2}$ parcial $=0,086$.

Interessante notar que em comparação aos animais que não receberam o quimioterápico, o percentual de fibras colágenas no parênquima pulmonar aumentou, em média, 35\%, 213\% e $257 \%$ naqueles os quais o docetaxel anidro foi administrado nas doses de 70, 140 e $210 \mathrm{mg} \cdot \mathrm{m}^{-2}$, respectivamente.

Os resultados das comparações emparelhadas provenientes da análise do efeito principal da aplicação do docexatel na deposição de fibras colágenas no parênquima pulmonar, revelou:

1. Em relação aos animais que não receberam o quimioterápico, o aumento médio (em pontos percentuais) dos que receberam o quimioterápico nas doses de 70, 140 e 210 mg.m ${ }^{-2}$, foi 
respectivamente: 2,24 (IC 95\%, 1,26 a 3,23), $p<0,001 ; 5,24$ (IC 95\%, 4,22 a 6,27), $p<$ 0,$001 ; 6,69$ (IC 95\%, 5,66 a 7,71), $p<0,001$.

2. Em relação aos animais que receberam o quimioterápico na dose de $70 \mathrm{mg} \cdot \mathrm{m}^{-2}$, o aumento médio (em pontos percentuais) dos que receberam o quimioterápico nas doses de 140 e 210 mg.m ${ }^{-2}$, foi respectivamente: 3,00 (IC 95\%, 1,99 a 4,00), $p<0,001 ; 4,44$ (IC 95\%, $3,43$ a 5,44$), p<0,001$.

3. Aumento médio de 1,44 pontos percentuais (IC 95\%, 0,39 a 2,48), $p=0,003$ nos animais que receberam docetaxel anidro na dose $210 \mathrm{mg} \cdot \mathrm{m}^{-2}$ comparativamente àqueles que receberam 140 mg.m ${ }^{-2}$ do quimioterápico.

A figura 4.9 abaixo ilustra os resultados da ação do docetaxel anidro na deposição de colágeno no parênquima pulmonar dos animais tratados ou não com dexametasona.

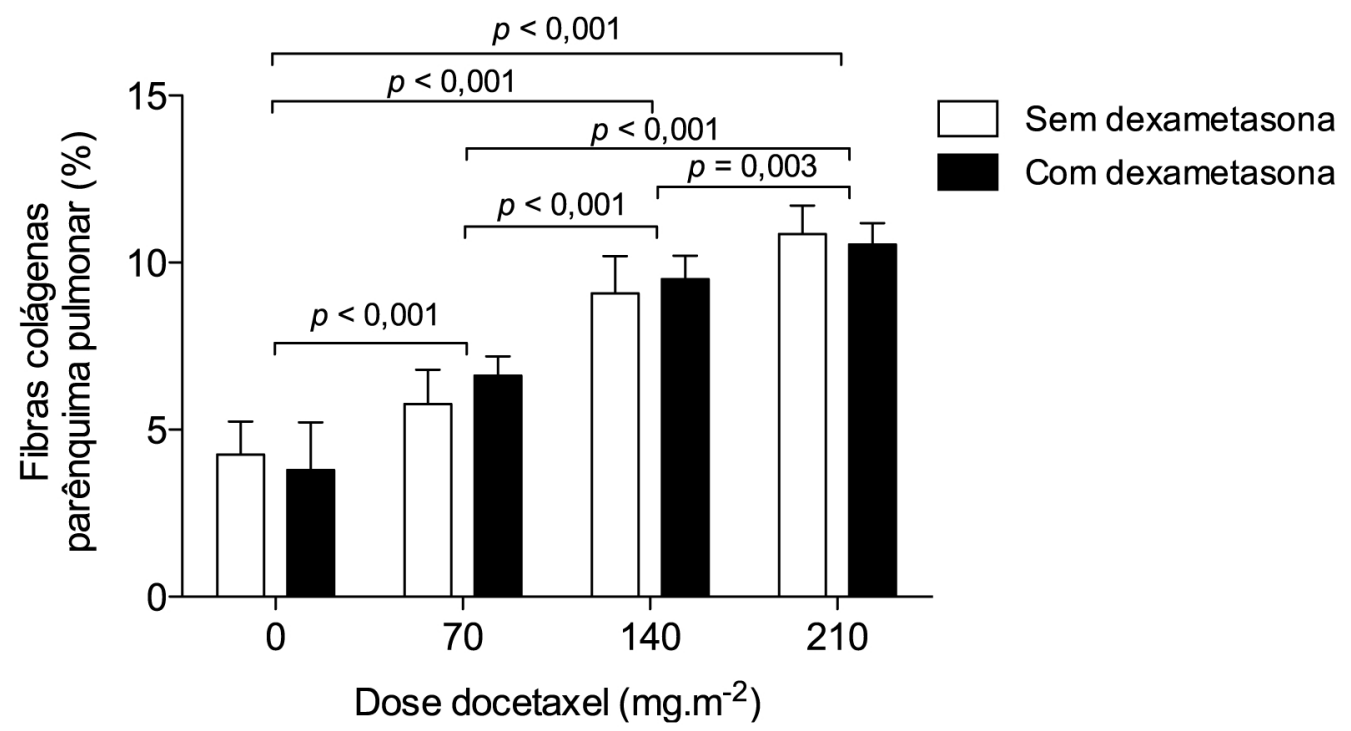

Figura 4.9: Efeito principal da administração do docetaxel anidro no percentual de fibras colágenas no parênquima pulmonar após 4 semanas da sua administração. As barras representam a média \pm desvio-padrão.

Houve interação significativa entre docetaxel anidro $x$ dexametasona na deposição de colágeno na vasculatura pulmonar, $F(1,52)=2,84, p=0,049, \eta^{2}$ parcial $=0,166$. Para os animais os quais o docetaxel anidro foi administrado na dose de $210 \mathrm{mg} \cdot \mathrm{m}^{-2}$, havia, em média, 30,9 \pm 13,1\% de fibras colágenas nos vasos pulmonares dos animais que não receberam dexametasona e 18,1 $\pm 8,6 \%$ na vasculatura pulmonar dos que receberam o corticoide, uma 
diferença média de 12,8\% (IC 95\%, 5,21 a 20,49), $F(1,52)=11,5, p=0,001, \eta^{2}$ parcial $=0,211$. Para as demais doses administradas de docetaxel anidro, não houve diferença significativa entre os animais que receberam ou não a dexametasona: $0 \mathrm{mg} \cdot \mathrm{m}^{-2}, F(1,52)=0,003, p=0,967, \eta^{2}$ parcial $=0,0001 ; 70 \mathrm{mg} \cdot \mathrm{m}^{-2}, F(1,52)=0,082, p=0,776, \eta^{2}$ parcial $=0,002 ; 140 \mathrm{mg} \cdot \mathrm{m}^{-2}$, $F(1,52)=0,778, p=0,383, \eta^{2}$ parcial $=0,018$, como ilustrado na figura 4.10 .

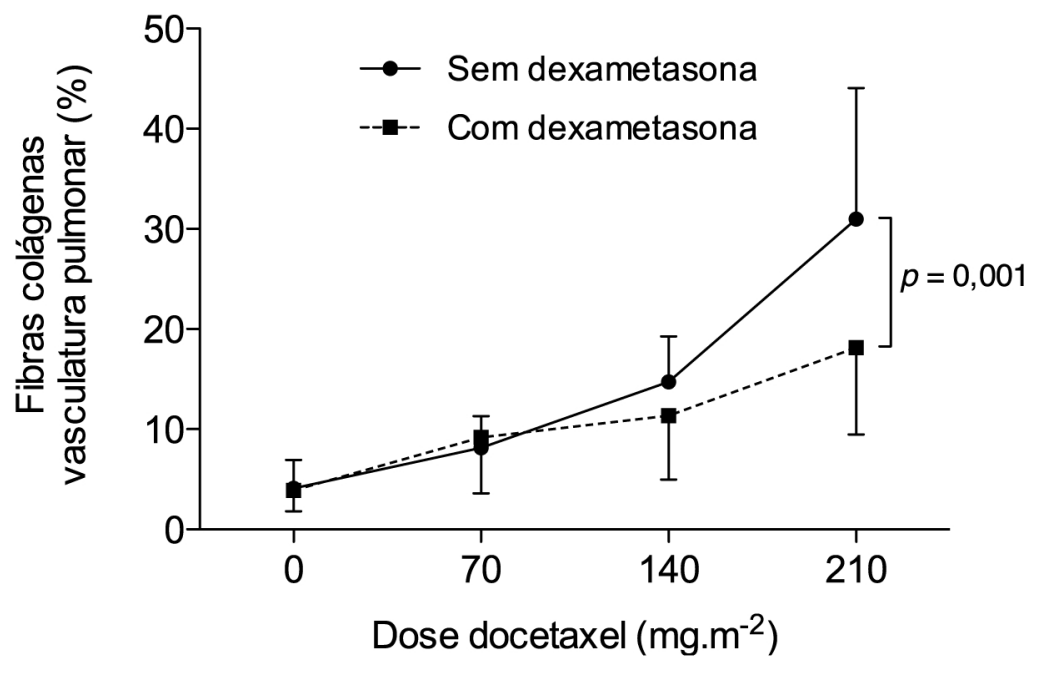

Figura 4.10: Efeito da interação docetaxel anidro $x$ dexametasona no percentual de fibras colágenas na vasculatura pulmonar após 4 semanas da sua administração. Os símbolos representam a média \pm desvio-padrão.

Analisando-se o efeito principal simples da administração do docetaxel anidro, a diferença na deposição de colágeno na vasculatura pulmonar foi significativa tanto para os animais que não receberam $F(1,52)=20,83, p<0,001, \eta^{2}$ parcial $=0,592$, quanto para os que receberam a dexametasona, $F(1,52)=4,85, p=0,005, \eta^{2}$ parcial $=0,253$.

Para os animais que receberam o docetaxel anidro nas doses de 0, 70, 140 e 210 mg.m ${ }^{-2}$ mas não receberam o corticoide, o percentual de fibras colágenas na vasculatura dos animais, foi: $4,08 \pm 2,84 ; 8,16 \pm 3,15 ; 14,73 \pm 4,54 ; 30,98 \pm 13,06$, respectivamente. Em comparação aos animais que não receberam o docetaxel anidro, a diferença média de 4,1 pontos percentuais não foi significativa em relação aos que receberam 70 mg.m ${ }^{-2}$ do quimioterápico, (IC 95\%, -5,13 a 13,47), $p=1$. Em contrapartida, a deposição de colágeno foi, em média, 10,6 pontos percentuais maior nos animais que o receberam na dose de $140 \mathrm{mg} \cdot \mathrm{m}^{-2}$ (IC 95\%, 0,2 a 21,2), $p=0,049$, e 26,9 pontos percentuais (IC 95\%, 16,8 a 37,0), $p<0,001$, naqueles nos quais o quimioterápico foi administrado na dose de 210 mg.m ${ }^{-2}$. Para as demais comparações emparelhadas, as diferenças 
médias (expressas em pontos percentuais), bem como os limites inferior e superior do intervalo de confiança de 95\% e o valor de $p$, foram: $70 x 140 \mathrm{mg} \cdot \mathrm{m}^{-2}$ : 6,56 (IC 95\%, -3,78 a 16,91), $p=0,51 ; 70 x 210$ mg.m ${ }^{-2}: 22,82$ (IC 95\%, 13,02 a 32,62), $p<0,001 ; 140 x 210$ mg.m ${ }^{-2}$ : 16,25 (IC 95\%, 5,26 a 27,24), $p=0,001$. (Figura 4.11).

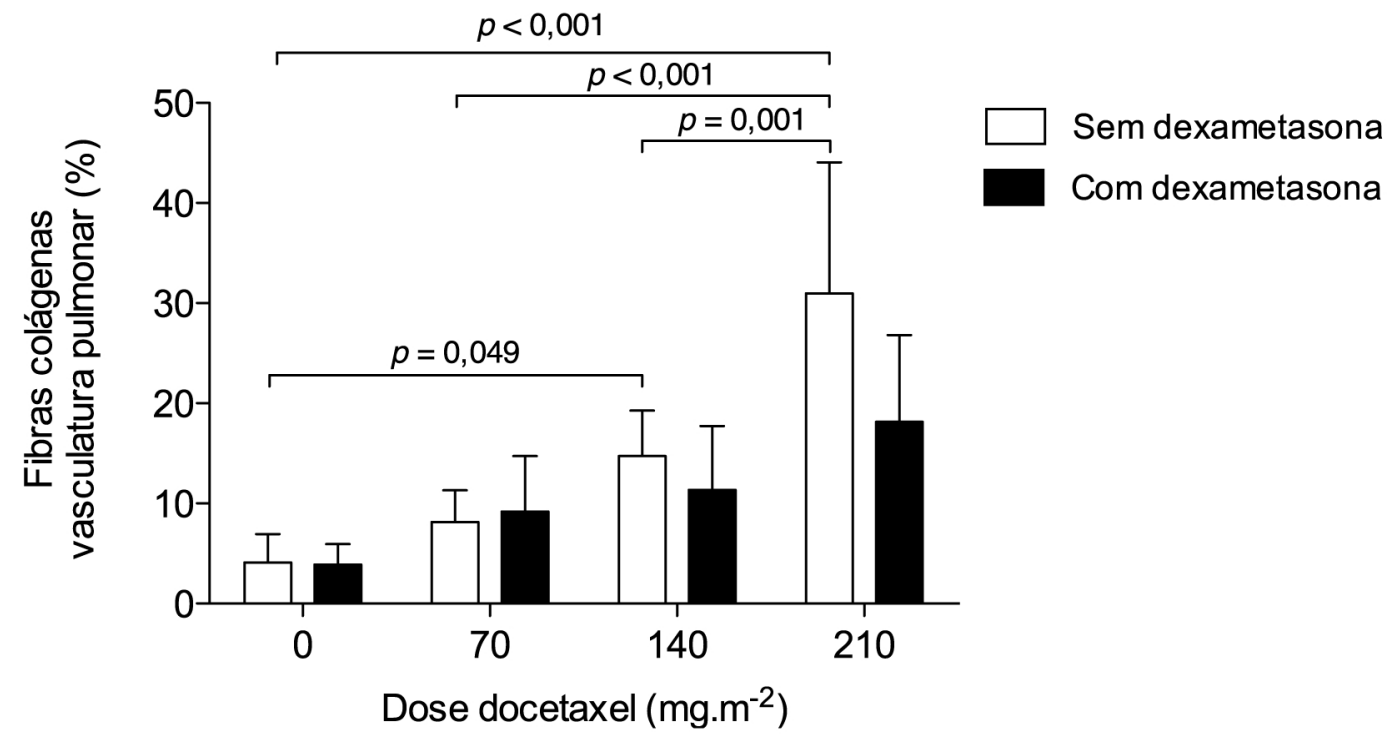

Figura 4.11: Efeito principal simples do docetaxel anidro (após 4 semanas da sua administração) no percentual de fibras colágenas na vasculatura pulmonar dos animais que não receberam a dexametasona. As barras representam a média \pm desvio-padrão.

Para os animais que receberam o docetaxel anidro nas doses de 0, 70, 140 e 210 mg.m ${ }^{-2}$ e que receberam o corticoide, o percentual de fibras colágenas na vasculatura dos animais, foi: $3,88 \pm 2,67 ; 9,17 \pm 2,67 ; 11,34 \pm 2,48 ; 18,13 \pm 2,67$, respectivamente. Em relação aos animais que não receberam o docetaxel anidro, os que receberam o quimioterápico na dose de 210 mg.m ${ }^{-2}$ observou-se, em média, aumento de 14,25 pontos percentuais (IC 95\%, 3,77 a 24,72), $p=0,003$. Por outro lado, não houve nenhuma diferença significativa para as demais comparações, e os resultados, expressos na forma de diferença em pontos percentuais, limites inferior e superior do intervalo de confiança de $95 \%$ e o valor de $p$, foram: $0 x 70 \mathrm{mg} \cdot \mathrm{m}^{-2}: 5,29$ (IC 95\%, -5,18 a 15,77), $p=1 ; 0 x 140$ mg.m ${ }^{-2}: 7,45$ (IC 95\%, -2,64 a 17,55), $p=0,284 ; 70$ $x 140$ mg.m ${ }^{-2}: 2,16$ (IC 95\%, -7,93 a 12,26), $p=1 ; 70 x 210$ mg.m ${ }^{-2}: 8,95$ (IC 95\%, -1,52 a 19,43), $p=0,136 ; 140 \times 210$ mg.m ${ }^{-2}: 6,79$ (IC 95\%, -3,31 a 16,89), $p=0,418$. (Figura 4.12. 


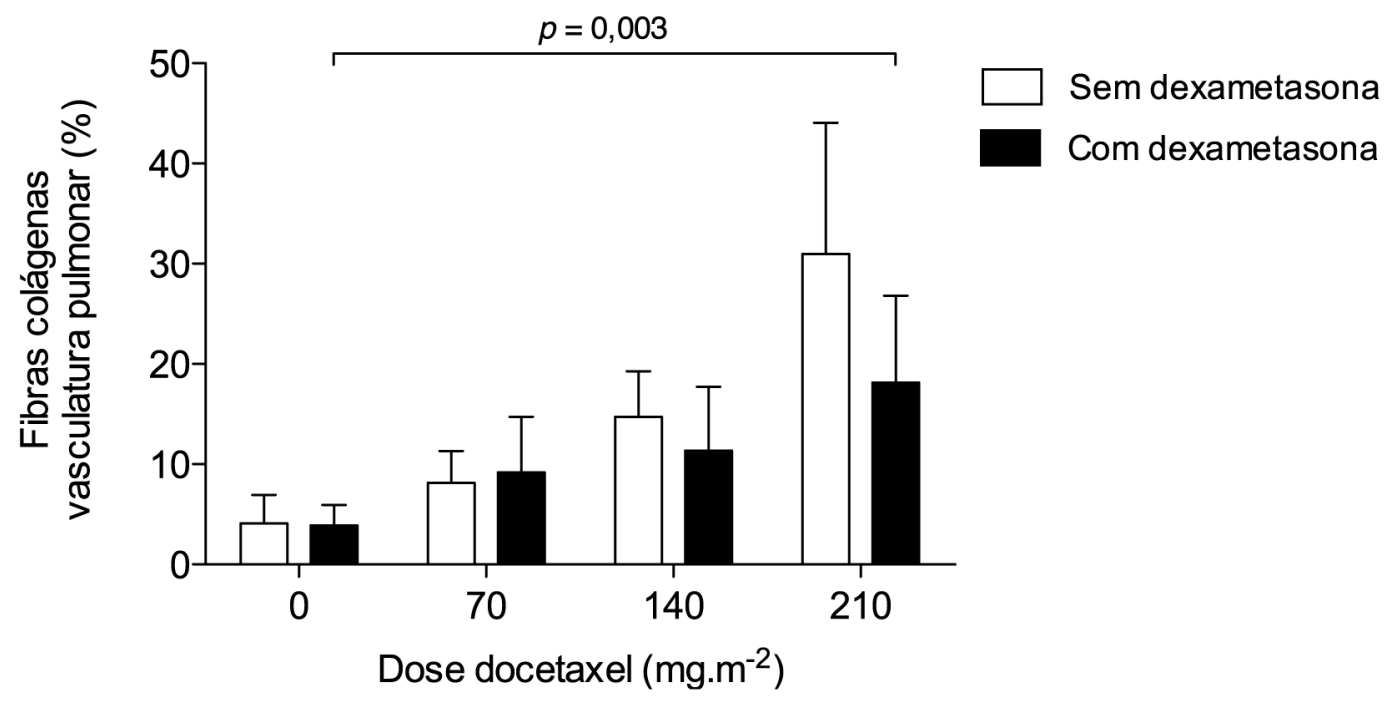

Figura 4.12: Efeito principal simples do docetaxel anidro (após 4 semanas da sua administração) no percentual de fibras colágenas na vasculatura pulmonar dos animais que receberam a dexametasona. As barras representam a média \pm desvio-padrão.

Em relação ao índice de edema alveolar, houve diferença significativa entre os grupos estudados após 4 semanas da administração dos medicamentos, e esta diferença se deveu ao efeito principal do docetaxel anidro, $F(3,52)=51,24, p<0,001, \eta^{2}$ parcial $=0,781$, ao efeito principal da dexametasona, $F(3,52)=2,32, p=0,021, \eta^{2}$ parcial $=0,117$, mas não pela interação docetaxel anidro $x$ dexametasona, $F(3,52)=1,35, p=0,27, \eta^{2}$ parcial $=0,086$.

Os resultados das comparações emparelhadas provenientes da análise do efeito principal da aplicação do docexatel no índice de edema alveolar, revelou:

1. Em relação aos animais que não receberam o quimioterápico, o aumento médio dos que receberam o quimioterápico nas doses de 70, 140 e $210 \mathrm{mg} \cdot \mathrm{m}^{-2}$, foi respectivamente: 1,02 (IC 95\%, 0,37 a 1,68), $p=0,001 ; 2,32$ (IC 95\%, 1,64 a 3,01), $p<0,001 ; 2,78$ (IC 95\%, $2,10$ a 3,46$), p<0,001$.

2. Em relação aos animais que receberam o quimioterápico na dose de $70 \mathrm{mg} \cdot \mathrm{m}^{-2}$, o aumento médio dos que receberam o quimioterápico nas doses de 140 e 210 mg.m ${ }^{-2}$, foi respectivamente: 1,30 (IC 95\%, 0,62 a 1,97), $p<0,001 ; 1,73$ (IC 95\%, 1,08 a 2,42), $p<$ 0,001 .

3. Nenhuma diferença significativa entre os animais que receberam docetaxel anidro na dose 140 mg. $\mathrm{m}^{-2}$ comparativamente àqueles que receberam $210 \mathrm{mg} \cdot \mathrm{m}^{-2}$ do quimioterápico, 
0,45 (IC 95\%, -0,24 a 1,14), $p=0,317$. Todos estes resultados estão ilustrados na figura 4.14.

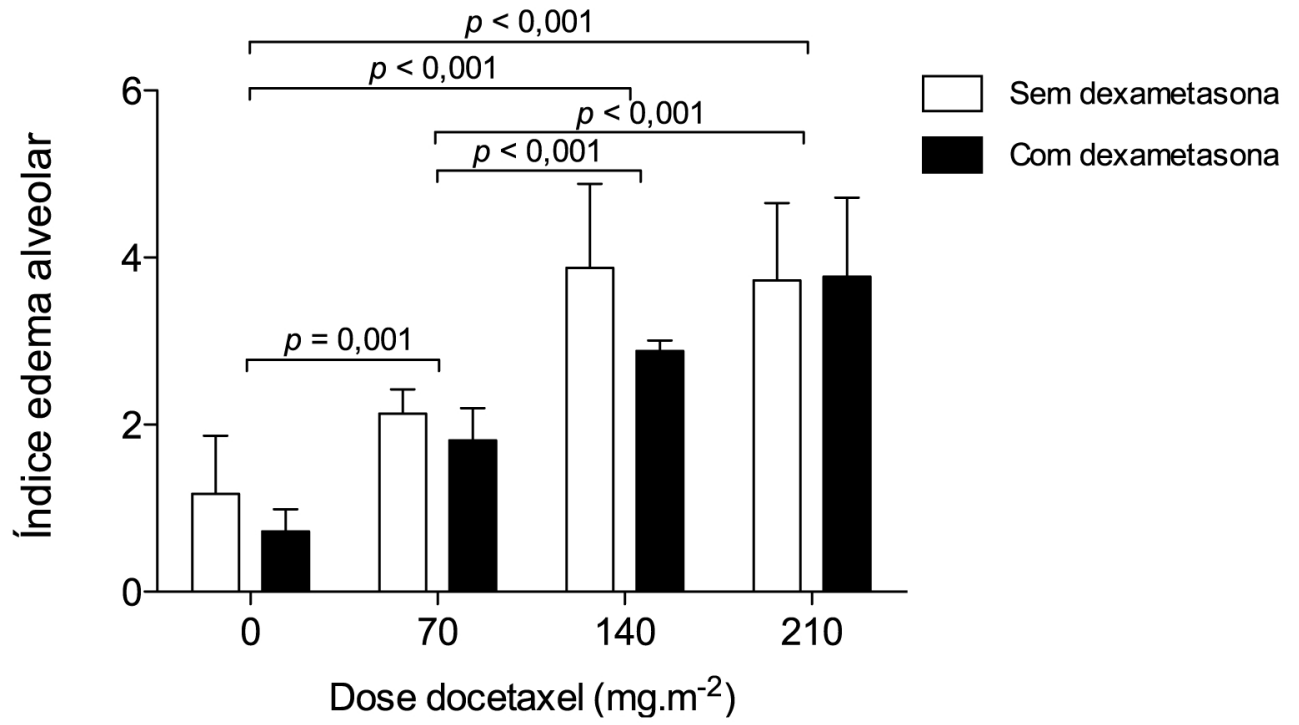

Figura 4.13: Efeito principal da administração do docetaxel anidro no índice de edema alveolar após 4 semanas da sua administração. As barras representam a média \pm desvio-padrão.

A análise do efeito principal da administração da dexametasona demonstrou que os animais que a receberam apresentaram, em média, o índice de edema alveolar 0,43 maior quando comparado aos que não receberam (IC95\%, 0,067 a 0,794), $p=0,021$ (Figura 4.14). 


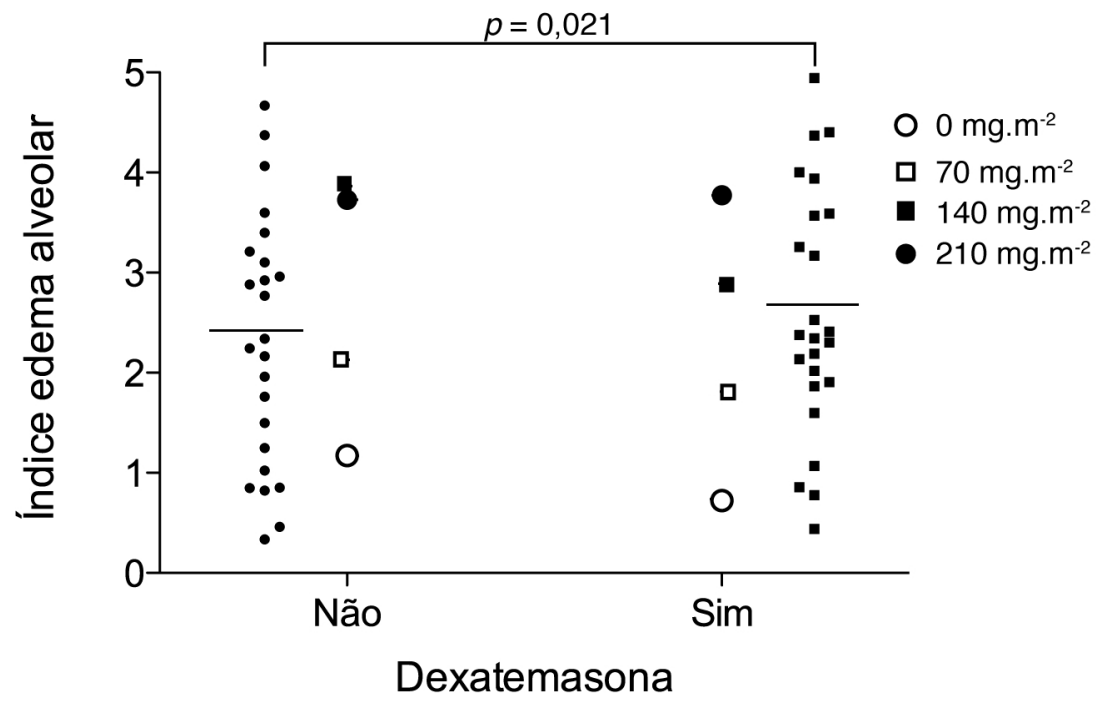

Figura 4.14: Efeito principal da administração do docetaxel anidro no índice de edema alveolar após 4 semanas da sua administração. Os símbolos representam a média; no diagrama de dispersão, a média é representada pelas barras horizontais 


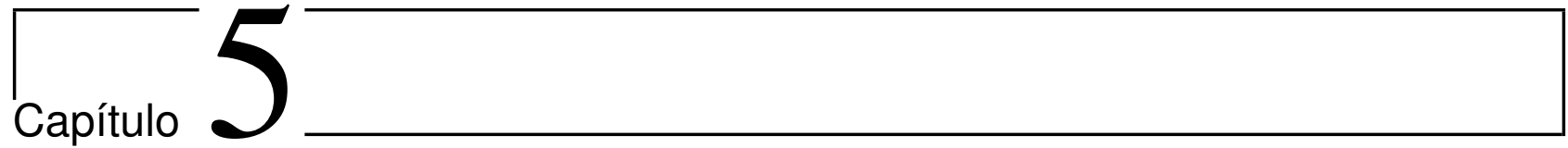

\section{Discussão}

No presente trabalho analisamos o efeito da aplicação do quimioterápico docetaxel nas propriedades mecânicas do sistema respiratório e dos pulmões e no remodelamento do tecido pulmonar e ainda se seria possível atenuar os danos pulmonares causados por este fármaco com o uso profilático de dexametasona. Para isto, foi utilizado um modelo experimental no qual o quimioterápico foi administrado via intraperitoneal em ratos da raça wistar em diferentes doses, com ou sem aplicação concomitante de dexametasona e avaliamos a função mecânica do sistema respiratório e os danos causados à estrutura do tecido pulmonar por estas medicações após 28 dias das suas aplicações.

Conforme exposto detalhadamente no capítulo anterior, observamos que houve maior ganho de peso nos ratos que receberam dexametasona em relação aos que não receberam $(p=0,008)$, porém este efeito não foi suficiente para minimizar a perda de peso gerada pela exposição ao docetaxel, já que todos os ratos tratados com este quimioterápico apresentaram menor ganho de peso em relação ao grupo controle $(p<0,001)$.

Em relação aos achados referentes às propriedades mecânicas do sistema respiratório e dos pulmões observamos diferenças significativas em três parâmetros: (i) elastância do sistema respiratório, que foi maior no grupo que recebeu $210 \mathrm{mg} \cdot \mathrm{m}^{-2}$ de docetaxel em ralação ao que recebeu placebo $(p=0,028)$; (ii) dissipação de energia no tecido pulmonar, que foi maior nos grupos que receberam docetaxel em relação aos que receberam placebo independentemente da dose aplicada $(p<0,01)$; (iii) conservação de energia no tecido pulmonar que também foi maior no grupo que recebeu 210 mg.m ${ }^{-2}$ em relação ao que recebeu placebo $(p=0,023)$. Já em relação 
aos dados histológicos, constatamos que houve maior acúmulo de colágeno no parênquima e na vasculatura pulmonar nos grupos que receberam docetaxel em ralação ao que recebeu placebo, sendo que no parênquima este efeito foi diretamente proporcional às doses administradas. O mesmo foi observado em relação ao índice de edema alveolar, que também foi maior nos grupos que receberam docetaxel anidro $(p<0,001)$ e diretamente proporcional às doses aplicadas. A exposição à dexametasona não produziu diferença significativa em nenhum parâmetro analisado, com exceção do colágeno na vasculatura pulmonar que foi maior no grupo tradado com 210 mg. $\mathrm{m}^{-2}$ sem dexametasona do que no grupo tratado com $210 \mathrm{mg} \cdot \mathrm{m}^{-2}$ com dexametasona $(p=$ $0,001)$.

\subsection{Considerações gerais acerca do modelo experimental utilizado}

Os modelos experimentais devem aproximar-se, ao máximo, da prática clínica. Há uma grande dificuldade para se fornecer regras específicas para a escolha do melhor modelo animal para determinado assunto devido às particularidades e influências, tanto do modelo animal, como de cada projeto de pesquisa e objetivos de estudo. A espécie Rattus novergcius é a mais utilizada em pesquisas e fornece contribuição nos estudos de genética, choque, sepse, metabolismo de lipídeos, efeito de vitaminas, icterícia, hipertensão, câncer, sistema mononuclear fagocitário, doenças infeciosas, toxicologia, endocrinologia e fisiologia reprodutiva. ${ }^{39-41}$ Nas últimas décadas, os ratos e camundongos têm sido ainda o modelo de primeira escolha para o estudo de uma grande variedade de doenças pulmonares, servindo para análise da elasticidade e resistência do sistema respiratório em diversas patologias como enfisema e fibrose pulmonar. ${ }^{42-44}$

Embora sejam amplamente utilizados como base para pesquisa experimental, os pulmões de ratos são consideravelmente diferentes dos pulmões humanos, apesar de existirem poucas publicações a respeito da comparação da arquitetura dos pulmões de ratos em relação as outras espécies. Dois fatores são particularmente importantes: (i) a pequena espessura do epitélio respiratório e (ii) o lúmen relativamente grande das vias aéreas nos ratos em comparação aos humanos, o que acredita-se que reduza a resistência ao fluxo de ar. ${ }^{40,41,45}$ Além 
disto, os ratos tem uma escassez ou completa ausência de glândulas submucosas e a presença de grande número de células claras. Exatamente qual o significado destas duas características em relação à anatomia é especulativa mas acredita-se que processos inflamatórios que podem comprometer substancialmente a função pulmonar de animais de grande porte (inclusive seres humanos) tenham pequeno efeito em ratos. ${ }^{39-41,45}$

Apesar destas diferenças, que devem ser levadas em consideração sempre que houver intenção de extrapolar os resultados obtidos para outras espécies, os modelos experimentais com ratos apresentam várias vantagens em relação aos demais modelos animais, tais como um sistema imunológico bem estudado, uma vasta gama de drogas e reagentes já testados, um ciclo reprodutivo curto, um genoma bem documentado, o advento de tecnologias transgênicas (que permitem trabalhar com animais geneticamente modificados), além do baixo custo e fácil manejo para alimentação e alojamento. ${ }^{41}$

Nos estudos clínicos envolvendo docetaxel, as doses administradas variam entre 60 e 100 mg.m $\mathrm{m}^{-2}$ em uma única aplicação por ciclo, sendo que a maioria deles utiliza 100 mg.m ${ }^{-2}$ a cada 21 dias. A maioria dos efeitos relevantes dos taxanes como a estabilização de microtúbulos contra a despolimerização, apoptose, radiossensibilização e antiangiogênese estão diretamente relacionadas à concentração do fármaco. ${ }^{46,47}$ No nosso estudo, reduzimos a DL 50 de forma a gerar um modelo que permitisse o ajuste de doses em intervalos regulares, com a intenção de responder se a toxicidade pulmonar causada por este quimioterápico também era proporcional à dose. O que observamos é que houve remodelamento pulmonar com repercussão na função mecânica respiratória em todos os ratos tratados com docetaxel, mesmo naqueles que receberam doses consideradas terapêuticas.

Em relação à dose de dexametasona utilizada em nosso estudo, que foi de $5 \mathrm{mg} / \mathrm{kg} / \mathrm{dia}$ concomitantemente à administração de docetaxel e nas 48 horas subseqüentes, procuramos novamente nos aproximar da prática clínica e dos modelos experimentais que estudaram o efeito deste corticosteroide na profilaxia de náuseas e vômitos induzidos por quimioterápicos e da fibrose pulmonar induzida por bleomicina. ${ }^{48,49}$

No nosso estudo, a técnica utilizada para a medida das propriedades mecânicas do sistema respiratório e dos pulmões foi a de oscilação forçada (TOF). Este método foi descrito em 
1956 por Dubois et. al. e é baseado na aplicação de oscilações de pressão de baixa amplitude ao sistema respiratório (geralmente na abertura das vias aéreas) e a análise da impedância do sistema respiratório através das medições das pressões e do fluxo correspondentes. ${ }^{50,51} \mathrm{~A}$ impedância mecânica descreve o efeito conjunto das propriedades resistivas, elásticas e inertivas do sistema respiratório e é caracterizada pela razão das amplitudes dos sinais de pressão e fluxo, conhecida como módulo de impedância e pela diferença no tempo entre os sinais, geralmente denominada diferença de fase. As variações da impedância são mais comumente representadas nos ensaios de oscilação forçada através dos componentes em fase, também conhecidos como reais e pelos componentes fora de fase, conhecidos como imaginários. Esta forma de representação permite uma relação direta com as propriedades mecânicas envolvidas no sistema respiratório, sendo o componente real usualmente denominada resistência e a componente imaginária frequentemente denominada reatância. A resistência está relacionada à viscosidade do ar enquanto que a reatância corresponde às diferentes formas de energia, relacionada à expansão do sistema respiratório (potencial) e à aceleração das massas (cinética). A inertância descreve o componente inercial da reatância: corresponde à energia necessária para movimentar a massa de partículas gasosas e também, tecido no sistema respiratório. ${ }^{50,52-56}$

Vários trabalhos anteriores mostram que os novos parâmetros obtidos por meio da TOF permitem uma avaliação mais detalhada da função mecânica do sistema respiratório, que seriam pouco perceptíveis com outros métodos, contribuindo para um melhor entendimento das alterações presentes em diversos processos patológicos. ${ }^{50,52}$

Os testes desenvolvidos com a TOF vêm tendo resultados bastante satisfatórios na avaliação da função mecânica do sistema respiratório de seres humanos e de animais de experimentação com doenças respiratórias. Essa técnica possibilita, por exemplo, diagnosticar o grau de reversibilidade da obstrução das vias aéreas superiores e inferiores, em doenças pulmonares intersticiais e em doenças envolvendo as paredes pulmonares. ${ }^{53,57,58}$

Desta forma, como pretendemos avaliar o efeito da administração do docetaxel e da dexametasona nas propriedades mecânicas do sistema respiratório, e nos componentes centrais e periféricos dos pulmões (vias aéreas e parênquima pulmonar, respectivamente), consideramos vantajosa a possibilidade de dissociação das diferentes medidas, contribuindo para melhor compreensão das alterações encontradas. 


\subsection{Avaliação do peso corporal}

A literatura é vasta em demonstrar a relação entre a massa corpórea e a toxicidade relacionada à quimioterapia, e ainda, que a toxicidade está relacionada às doses administradas e é diferente para cada órgão e tecido corporal, sendo comum menor ganho ponderal em esquemas mais potentes de quimioterapia. ${ }^{59-62} \mathrm{O}$ efeito dos quimioterápicos no peso corporal está relacionado a toxicidade destes fármacos ao trato gastrointestinal. Entre os efeitos colaterais mais comuns relacionados ao docetaxel estão a mucosite, náuseas e vômitos, disfagia, odinofagia e anorexia, sendo que a mucosite pode ocorrer em até $52 \%$ dos casos. ${ }^{63}$ Estes efeitos também foram demonstrados em nosso experimento, onde observamos que animais tratados com doses mais altas de docetaxel apresentaram menor ganho ponderal em relação aos controles, concordando, portanto, com a literatura vigente.

Observamos também que houve maior ganho de peso entre os animais que receberam dexametasona em relação aos que não receberam. Este dado também converge com a literatura, já que os glicocorticoides são considerados obesogênicos. Conforme descrito por Sarcev et. al., ${ }^{64}$ o uso de corticoides está associado ao aumento do apetite e ao ganho de peso, inclusive sendo indicado para esta finalidade no tratamento de pacientes com caquexia neoplásica, efeito este, que é observado mesmo quando são utilizados por um curto período de tempo. ${ }^{64-66}$ Sabe-se ainda que os glicocorticoides atuam na biologia dos adipócitos, regulando a lipólise e as funções endócrinas, agindo através de diferentes mecanismos que culminam para o ganho ponderal. ${ }^{67}$

Apesar de observarmos um maior ganho de peso nos ratos que utilizaram dexametasona em relação aos que não utilizaram, 100\% dos ratos tratados com docetaxel apresentaram menor ganho de peso em ralação ao grupo controle. Salminen et al, demonstrou que em pacientes com câncer de mama politratadas doses acima de $100 \mathrm{mg} \cdot \mathrm{m}^{-2}$ de docetaxel, apesar de efetivas, não foram factíveis devido aos efeitos colaterais importantes, destacando diarreia e mucosite, sendo necessária redução de dose em mais da metade das pacientes. ${ }^{68}$ É possível que os efeitos colaterais relacionados às altas doses de quimioterápico utilizadas no nosso estudo tenham se sobrepujado ao efeito de ganho de peso proporcionado pela dexametasona, justificando nossos achados. 


\subsection{Correlação entre as propriedades mecânicas do sis- tema respiratório e os achados histológicos}

Existe uma complexa rede de macromoléculas chamada de matriz extracelular que desempenha um papel essencial na sustentação estrutural dos pulmões. Os principais elementos da matriz extracelular são as fibras elásticas, colágenas, as proteoglicanas e as glicosaminas, sendo que dentre estas, as fibras colágenas são as presentes em maior quantidade, constituindo $70 \%$ do interstício pulmonar. Nas áreas de trocas gasosas, a matriz extracelular tem um papel bastante dinâmico, a fim de adequar as constantes alterações de volume pulmonar que acompanham a inspiração e a expiração. As fibras colágenas estão presentes em todas as estruturas principais, incluindo vias aéreas, vasos sanguíneos, interstício do parênquima pulmonar e a membrana basal das células endoteliais e epiteliais. Qualquer alteração na estrutura, quantidade ou geometria de sua distribuição pode repercutir e alterar a função pulmonar.

O revestimento epitelial dos alvéolos é formado por células especializadas, denominadas pneumócitos tipo I e II e uma rede densa de capilares faz contato com toda a superfície alveolar, sendo que as lâminas basais do epitélio (pneumócito tipo I) e do endotélio vascular podem fundir-se. ${ }^{69,70}$

Os mecanismos de estabilidade mecânica e a distensão do parênquima pulmonar se tornam ainda mais complexos se considerarmos a presença do surfactante pulmonar, que é composto de lipídeos e proteínas, e ajuda a reduzir o trabalho da inspiração diminuindo a tensão superficial dos alvéolos (o que permite que alvéolos de diâmetros diferentes possuam a mesma pressão), reduzindo assim a retração elásstica dos pulmões, tornando-os mais complacentes e estáveis mecanicamente. Este mecanismo, somado à interdependência mecânica dos alvéolos ajuda a estabilizá-los e se opõem ao seu colapso. ${ }^{69}$

No nosso estudo, na análise das propriedades mecânicas do sistema respiratório e dos pulmões ficou demonstrado aumento significativo do amortecimento do tecido pulmonar nos grupos tratados com docetaxel em relação aos que utilizaram placebo. Ainda houve elevação significativa nas medidas de elastância do sistema respiratório e de conservação de energia no tecido pulmonar, que também foi maior nos grupos tratados com docetaxel. 
Nos modelos de estudo de fibrose pulmonar idiopática disponíveis na literatura, observamos que a proliferação de tecido conjuntivo, que também encontramos no nosso experimento, pode reduzir os volumes pulmonares, deslocando a curva de volume x pressão para direita. ${ }^{71-74}$ Esta condição também é vista em outras situações patológicas como na sarcoidose e nas lesões pulmonares quimicamente induzidas. ${ }^{75-78}$

De fato, houve maior acúmulo de fibras colágenas no parênquima e na vasculatura pulmonar dos grupos tratados com docetaxel, mesmo em doses consideradas terapêuticas, em relação aqueles que receberam placebo. Além disto, observamos que estas alterações foram diretamente proporcionais à dose aplicada do quimioterápico. Na literatura não há modelos claros que estudem a correlação entre as alterações histológicas encontradas e as propriedades mecânicas pulmonares, porém existem relatos isolados que mostram fibrose pulmonar em pacientes que foram submetidos à quimioterapia com docetaxel..$^{79-82}$

Nos pulmões já foram identificados mais de 20 tipos diferentes de colágeno. Os colágenos fibrilares (tipos I, II, III, V e XI) são os mais abundantes e compões cerca de 20 a $30 \%$ do peso seco pulmonar e tem como principal função conferir força tênsil a todos os componentes distensíveis dos pulmões. ${ }^{83-85}$ Além dos vários subtipos, ainda é possível classificar o colágeno pulmonar em maduro, que é aquele presente usualmente na estrutura e composição normal do tecido e o imaturo que é aquele neossintetizado, após o processo de remodelamento tecidual. ${ }^{85}$

Considerando a função primordial das fibras colágenas, de atuar em todos os componentes distensíveis dos pulmões, a correlação entre acúmulo de colágeno e as alterações na mecânica ventilatória são plausíveis do ponto de vista fisiopatológico. É esperado que quanto maior for a deposição de colágeno, maior seja a elastância, ocasionando um aumento da energia conservada no tecido pulmonar e, portanto, maior retração elástica alveolar, exatamente como foi demonstrado no nosso experimento.

Outro aspecto importante que deve ser levado em conta quando se correlaciona histologia e função pulmonar é a presença de condições que interferem na capacidade de expansão dos pulmões. No nosso estudo encontramos um aumento significativo no índice de edema alveolar entre os ratos tratados com docetaxel em comparação com os que receberam placebo, o que possivelmente também contribuiu para um aumento da elastância. Um exemplo típico deste 
mecanismo é a Síndrome do Desconforto Respiratório Agudo, onde há extravasamento de fluidos para o espaço alveolar com conseqüente aumento da tensão superficial alveolar, ocorrência de atelectasias e redução da complacência pulmonar. ${ }^{86}$

A resistência das vias respiratórias juntamente com a resistência do tecido pulmonar recebem com frequência a designação de resistência pulmonar, sendo que as vias aéreas contribuem com $80 \%$ desta resistência e o tecido pulmonar com os outros $20 \%{ }^{69}$ Através do modelo de fase constante utilizado neste estudo, foi possível dissociar estes os dois componentes de resistência pulmonar. Do ponto de vista fisiopatológico, é perfeitamente esperado que o aumento do depósito de fibras colágenas no parênquima pulmonar contribua para aumentar o amortecimento do tecido pulmonar, como foi visto nos nossos resultados. Por outro lado, observamos que não houve nenhuma influência da aplicação de docetaxel nos valores de resistência das vias aéreas centrais dos pulmões.

Alguns modelos de fibrose pulmonar idiopática mostram um acometimento heterogêneo em relação ao remodelamento e as propriedades viscoelásticas dos pulmões, sendo que quanto mais avançada é a doença maior é o grau de fibrose em áreas consideradas mais ativas para influenciar nas propriedades mecânicas pulmonares. ${ }^{71,74}$ Este efeito pode ter influenciado no fato de encontrarmos alterações significativas nas medidas de resistência do parênquima pulmonar que não se refletiram quando analisamos o sistema respiratório como um todo.

Ainda precisamos levar em consideração que a correlação entre as alterações histológicas e as propriedades mecânicas pulmonares dependem da intensidade da lesão, se esta lesão é aguda ou crônica, reversível ou não. O asbesto, por exemplo, é capaz de alterar a estrutura do tecido pulmonar, com conseqüente alteração de sua função, produzindo alterações mensuráveis após 24 horas da sua administração intra-traqueal, principalmente por causa da lesão inflamatória aguda produzida por esta substância. ${ }^{87}$ Comparativamente, a bleomicina, utilizada na produção de modelos para estudo da fibrose pulmonar idiopática, é capaz de induzir lesão com alteração das propriedades mecânicas pulmonares em camundongos somente 21 dias após a sua instilação por via intra-traqueal, quando a concentração tecidual de colágeno ultrapassa $300 \mu \mathrm{cg}$ (valores 3 vezes acima do controle). ${ }^{88}$ Ou seja, alterações mensuráveis na histologia podem correlacionarse de forma não linear com as disfunções mecânicas, dependendo da intensidade e do tempo necessário para que um fator cause impacto no outro. 
É importante lembrar que todos os casos de pneumonia induzida por taxanes ocorreram após exposições a múltiplos quimioterápicos (poliquimioterapia) ou após múltiplas exposições ao docetaxel, e que no modelo experimental que estudamos, os animais foram expostos a uma única aplicação da droga. É possível que a exposição contínua ao docetaxel possa induzir um maior grau de lesão dos pulmões e que estas alterações possam, eventualmente, repercutir mais claramente nas propriedades mecânicas da respiração. Portanto, é importante ressaltar a possibilidade de amplificação e cronificação das lesões encontradas neste estudo após múltiplas aplicações da medicação, sendo necessários, portanto, outros estudos, com delineamento que valorize a exposição contínua a este fármaco, ou seja delineamentos que investiguem os efeitos da interação do tempo e das múltiplas aplicações de quimioterápicos nas estruturas e funções pulmonares.

Por fim, precisamos levar em consideração ainda que existem outros fatores, que não foram analisados no nosso experimento, que podem influenciar ativamente no funcionamento mecânico do sistema respiratório, como a presença e a qualidade do surfactante pulmonar. Alguns modelos de fibrose pulmonar quimicamente induzida, como por exemplo a que ocorre com o uso de amiodarona, alteram significativamente o surfactante pulmonar, interferindo diretamente na retração elástica e na complacência dos pulmões. ${ }^{89}$ Neste ínterim é plausível supor numa alteração do surfactante pulmonar induzida pela administração do docetaxel. Se este fenômeno ocorre de fato, é razoável especular o seu efeito e contribuição para o aumento a conservação de energia no tecido pulmonar observado neste estudo. Infelizmente, ainda não há na literatura, pelo menos até a data da redação desta dissertação, estudos que tenham investigado tal questão, o que, no nosso entender, precisa ser esclarecida.

\subsection{Mecanismo fisiopatológico da lesão pulmonar indu- zida pelo docetaxel}

Conforme descrito anteriormente, a toxicidade pulmonar induzida pelo docetaxel é uma realidade presente na prática clínica, com uma prevalência em torno de 10\%, mas não há descrição na literatura de nenhum modelo experimental que explique a fisiopatologia das 
alterações que culminam com a fibrose pulmonar. ${ }^{90,91}$

Mesmo sem estudos direcionados para preencher esta lacuna, podemos levantar uma hipótese baseada no mecanismo de ação do docetaxel: inibição da despolimerização dos microtúbulos e na indução da apoptose celular.

A apoptose é um processo natural de morte celular programada. O entendimento clássico da literatura é de que a apoptose é um evento benigno necessário para a depuração das células que não são mais úteis ou funcionais no organismo. ${ }^{92,93}$ Todavia, Johnson et. al. descrevem que recentes achados sugerem que a apoptose celular é um processo que pode ter conseqüências para os tecidos adjacentes, servindo como gatilho para o início e a propagação do processo de fibrose em diferentes órgãos. ${ }^{94}$ Altos níveis de apoptose foram identificados em todos os tipos de fibrose, sendo que características da fibrose como aumento de células semelhantes aos miofibroblatos ("mioFB-likes"), aumento da síntese e diminuição da degradação do colágeno, podem ser observados na cicatrização de feridas, fibrose renal e pulmonar e na vasculopatia crônica induzida pelo transplante. ${ }^{94,95}$

Além disto, considera-se que a apoptose tenha ainda um efeito indireto na modulação da resposta imune, liberando citocinas e fatores de crescimento que estimulam o crescimento tecidual e conseqüentemente a fibrose. Já foi demonstrado in vitro por Laplante et. al., que a injeção subcutânea de agentes estimulantes de apoptose de células endoteliais foi suficiente para causar aumento e persistência de miofibroblastos neste tecido. ${ }^{96}$

Wang et. al. também demonstraram, através de um modelo experimental utilizando ratos, que a introdução de macrófagos indutores de apoptose por via intratraqueal resultou em um aumento da deposição de colágeno e contribuiu para iniciar e propagar o processo de fibrose pulmonar. ${ }^{97}$

Desta forma, imaginamos que a indução da apoptose gerada pelo docetaxel pode ser uma das explicações para o desenvolvimento da fibrose pulmonar observada no nosso experimento, porém outros estudos específicos para este fim, que identifiquem a presença de todos os componentes da cascata que culmina com a fibrose pulmonar são necessários para testar esta hipótese. 


\subsection{Efeito do corticoide nas propriedades mecânicas pul- monares e nos achados histológicos}

Embora o efeito da dexametasona seja importante na redução de síndrome de retenção hídrica induzida pelo docetaxel, como é evidenciado na literatura, ${ }^{98}$ não conseguimos demonstrar experimentalmente o seu benefício na redução do remodelamento pulmonar e na atenuação das alterações mecânicas induzidas por este quimioterápico. Contudo, alguns pontos devem ser levados em consideração:

1. Apesar de muito utilizados para o tratamento das doenças inflamatórias pulmonares, agudas e crônicas, pouco se sabe sobre a penetração dos glicocorticoides nos pulmões. Modelos experimentais com prednisona e prednisolona demonstram que o aumento da concentração destes fármacos nos pulmões não é diretamente proporcional ao aumento plasmático. ${ }^{89}$

2. A exemplo das lesões pulmonares induzidas por agentes inalatórios, não há na literatura nenhum estudo baseado em modelos animais que evidencie que corticoides possam agir de forma profilática. ${ }^{99}$ Alguns estudos inclusive demonstram que na fase de recuperação da lesão aguda pulmonar induzida por agentes inalados não hidrossolúveis, como ozônio e dióxido de nitrogênio, os corticoides dificultam a divisão das células alveolares tipo II e a diferenciação das células alveolares tipo II em tipo I, que são importantes para reeptelização dos alvéolos e para remoção do excesso de água do seu interior. ${ }^{99}$ Por outro lado, em estudos com seres humanos envolvendo a exposição a agentes solúveis em água como a amônia, por exemplo, o tratamento com corticoides reduziu a resistência das vias aéreas e elevou a saturação de oxigênio. ${ }^{100,101}$

3. Sabe-se que a resposta à dexametasona é dependente da dose utilizada e do tempo de uso. Em um estudo publicado por Jonasson et al, onde foi testada a ação da dexametasona na redução da hiperresponsividade das vias aéreas e na inflamação causada pela inalação de clorina, foi evidenciado que nas primeiras horas após a administração, altas doses de dexametasona são mais efetivas do que doses convencionais para reduzir a resposta inflamatória e ainda que a administração imediata de dexametasona após a inalação deste 
agente alquilante foi mais eficaz do que a administração tardia, após as primeiras 12 horas. ${ }^{101}$

4. Há na literatura evidências de que os corticoides reduzem a atividade de algumas interleucinas relacionadas ao processo inflamatório, dentre elas a IL-17. Em estudos de fibrose pulmonar induzida por radioterapia foi evidenciado que a expressão da IL-17 estava presente após a primeira semana, com pico de ação após 14 dias, de modo que o uso contínuo de baixas doses de dexametsona pelo período de 1 mês reduziu de forma significativa a fibrose. ${ }^{102}$

5. Por último, vale a pena ressaltar que, embora não exista literatura extensa acerca do tratamento da pneumonia induzida pelo docetaxel, os relatos de casos demonstram que há melhora significativa da função pulmonar nos casos tratados com corticoides em relação aos não tratados, sugerindo benefício com esta abordagem. ${ }^{90,103,104}$

Considerando todas estas variáveis, a questão do uso da dexametasona para evitar as alterações histológicas e funcionais dos pulmões após o tratamento com docetaxel ainda não está encerrada. Seriam necessários outros estudos com delineamentos diferentes, explorando outras doses e formas de administração para melhor investigação do seu uso na profilaxia da lesão pulmonar induzida pelo docetaxel.

No nosso estudo, utilizamos a dose de $5 \mathrm{mg} \cdot \mathrm{kg}^{-1}$ baseada em modelos de tratamento de fibrose pulmonar idiopática e ainda tentando aproximação com a prática clínica em que os corticoides são administrados concomitantemente e nas 48 horas subsequentes a administração dos quimioterápicos para evitar os efeitos colaterais de retenção hídrica e de náuseas e vômitos.

\subsection{Críticas ao estudo}

Uma das críticas que deve ser levada em consideração, é em relação ao delineamento do trabalho, que utilizou doses crescentes de docetaxel, incluindo doses altas que não são factíveis na prática, com objetivo de responder se os achados encontrados seriam proporcionais as doses ou não. Além disto, utilizamos uma única aplicação, enquanto na prática este fármaco é utilizado por mais ciclos. Somado a isto, o corticoide também foi utilizado em dose fixa e 
por apenas três dias, sendo que há estudos que demonstram maior benefício com o seu uso contínuo. $^{102}$

Em relação às medidas morfométricas do tecido pulmonar, nos dedicamos em avaliar somente a concentração de fibras colágenas no parênquima e na vasculatura pulmonar e não avaliamos, por exemplo a concentração de fibras elásticas nos pulmões. Embora a presença disseminada de colágeno nos pulmões represente necessariamente alteração estrutural no órgão, nosso delineamento não contemplou o estudo de outros elementos celulares e alterações morfológicas que caracterizam a pneumonia intersticial. Neste sentido, também seria interessante nos próximos estudos, investigar se o docetaxel é capaz de produzir alguma alteração a ultraestrutura do tecido pulmonar como também alterações no surfactante.

Precisamos considerar ainda a possibilidade das alterações mecânicas do sistema respiratório e dos pulmões terem sido influenciadas por outros fatores não relacionados ao remodelamento pulmonar. A miosite associada ao docetaxel foi descrita pela primeira vez em 2005 e embora seja considerada complicação rara, poderia ser uma explicação plausível para as alterações encontradas na elastância do sistema respiratório. ${ }^{105,106}$ Novos estudos, com delineamento específico seriam necessários para avaliar o possível comprometimento da musculatura intercostal após o uso do docetaxel uma vez que inexiste qualquer modelo experimental que avalie este efeito.

Outro elemento que deve ser discutido é o método de quantificação do colágeno que utilizamos, que não foi capaz de fazer a diferenciação entre colágeno maturo do colágeno imaturo, ou seja neossintetizado após o processo de remodelamento tecidual. Existem duas formas de analisar o conteúdo colágeno de um tecido: por diluição ácida ou por diluição neutra. ${ }^{107,108}$ A forma mais comum é realizada através da dosagem de hidroxiprolina, que chega a compor 13,5\% do colágeno em diluição ácida. ${ }^{109,110}$ Entretanto, até 5\% do colágeno pulmonar não poderia ser avaliado por este método. ${ }^{111}$ Outra alternativa é fazer a medida pelo método de corante de Sírius vermelho, utilizando a luz polarizada para a sua quantificação. Este método tem por base a ligação do corante no complexo [Gly-x-y] presente na tripla hélice de todas as fibras colágenas, de todos os subtipos. ${ }^{111}$ A crítica a este último é a falta de especificidade na determinação do subtipo do colágeno estudado, inclusive pela falta de dissociação tecidual, não podendo ser definido se a medida corresponde, ou não, ao colágeno neossintetizado. Outro pro- 
blema é que inexistem estudos comparando os métodos de análise quantitativa e qualitativa o que torna a comparação entre trabalhos muito difícil, analogamente, deste estudo experimental com outros.

Finalmente, não podemos esquecer também das diferenças entre a anatomia e a fisiologia dos pulmões dos ratos em relação aos pulmões humanos, de modo que é preciso cautela ao extrapolar os resultados encontrados neste estudo para os seres humanos, dadas as suas singularidades. Por todas as questões expostas acima fica claro que este trabalho não encerra o estudo acerca da ação dos taxanes na arquitetura do parênquima pulmonar e nem descarta a influência do corticoide nestas alterações. É preciso explorar se os efeitos na morfologia e na função mecânica dos pulmões de várias aplicações em doses baixas são semelhantes à uma única aplicação em dose mais elevada e ainda se a aplicação contínua modularia os efeitos encontrados neste estudo.

De toda forma, e em síntese, este estudo demonstrou que o docetaxel, mesmo em dose única provoca acúmulo de colágeno nos pulmões dos ratos e interfere no funcionamento mecânico pulmonar e que a dexametasona, nas doses e intervalos habituais (semelhantes às utilizadas corriqueiramente na prática clínica) não evitam, e nem sequer atenuam estas alterações. 
Capítulo

\section{Conclusões}

O docetaxel aplicado em dose única via intraperitoneal elevou a elastância do sistema respiratório bem como o amortecimento e a conservação de energia no tecido dos pulmões, além de ter aumentado a deposição de colágeno no parênquima e na vasculatura pulmonar de ratos Wistar. Estas alterações foram diretamente proporcionais às doses aplicadas, e a administração de dexametasona, na dose de $5 \mathrm{mg} \cdot \mathrm{Kg}^{-1}$ imediatamente após a aplicação de docetaxel e nas 48 horas subsequente, não impediu e nem sequer atenuou as alterações mecânicas e histológicas causadas pelo quimioterápico. 


\section{Referências Bibliográficas}

[1] Instituto Nacional de Câncer José Alencar Gomes da Silva. Estimativa 2014: incidência de Câncer no Brasil. Inca, 2014.

[2] Curado MP, Edwards B, Shin HR, Storm H, Ferlay J, and Heanue M. Cancer incidence in five continents. IARC scientific publications, 160, 2007.

[3] Souza MVN. Novos produtos naturais capazes de atuar na estabilização de microtúbulos, um importante alvo no combate ao câncer. Quim Nova, 27:308 - 312, 2004.

[4] Wall ME and Wani MC. Camptothecin and taxol: Discovery to Clinic - thirteenth Bruce F. Cain Memorial Award Lecture. Cancer Res, 55:763 - 760, 1995.

[5] Rowinsky EK. The taxanes: dosing and scheduling. Oncology (Williston Park), 11 (3 Suppl 2):7 - 19, 1997.

[6] Fossella FV, Lee JS, and Berille J. Summary of phase 2 data of docetaxel (taxotere), an active in the first- and second-line treatment of non-small-cell lung cancer. Semin Oncol, 22 (2 Suppl 4):22 - 29, 1995.

[7] Kaye SB. Docetaxel in the treatment of solid tumors others than breast and lung cancer. Semin Oncol, 2:30 - 33, 1995.

[8] Osanto S and Van Poppel H. Emerging novel therapies for advanced prostate cancer. The Adv Urol, 4:3 - 12, 2012. 
[9] Fujimoto N, Shiota M, Kubo T, and Matsumoto T. Novel therapeutic strategies following docetaxel-based chemotherapy in castration-resistant prostate cancer. Expert Rev Clin Pharmacol, 3:785 - 795, 2010.

[10] Serpa Neto A, Tobias-Machado M, Wroclawski ML Kaliks R, Pompeo AC, and Del Giglio. Ten years of docetaxel-based therapies in prostate adenocarcinoma: a systematic review and meta-analysis of 2244 patients in 12 randomized clinical trials. Clin Genitourin Cancer, 9:115 - 123, 2011.

[11] Urakami S, Yoshino T, Kikuno N, Imai S, Honda S, Yoneda T, Kishi H, Shigeno K, Shiina H, and Igawa M. Docetaxel-based chemotherapy as second-line treatment for paclitaxelbased chemotherapy-resistant hormone-refractory prostate cancer: a pilot study. Urology, $65: 543-548,2005$.

[12] Vassilis G, Ardavanis A, Tsiafaki X, Agelidou A, Mixalopoulou P, Anagnostopoulou O, Ziotopoulos P, Toubis M, Syrigos K, Samaras N, Polyzos A, Christou A, Kakolyris S, Kouroussis C, Androulakis N, Samonis G, and Chatzidaki D. Vinorelbine plus cisplatinversus docetaxel plus gemcitabine in advanced non-small-cell lung cancer: A phase 3 randomized trial. J Clin Oncol, 1:2937 - 2945, 2005.

[13] Hanna N, Neubauer M, Yiannoutsos C, McGarry R, Arseneau J, Ansari R, Reynolds C, Govindan R, Melnyk A, Fisher W, Richards D, Bruetman D, Anderson T, Chowhan N, Nattam S, Mantravadi P, Johnson C, Breen T, White A, and Einhorn L. Phase III study of cisplatin, etoposide, and concurrent chest radiation with or without consolidation docetaxel in patients with inoperable stage 3 non-small-cell lung cancer: The Hoosier oncology group and U.S. Oncology. J Clin Oncol, 10:5755 - 5760, 2008.

[14] Dunsford ML, Mead GM, Bateman AC, CooK T, and Tung K. Severe pulmonary toxicity in patients treated with a combination of docetaxel and gemcitabine for metastatic transitional cell carcinoma. Ann Oncol, 10:943 - 947, 1999.

[15] Ho MY and Mackey JR. Presentation and management of docetaxel-related adverse effects in patients with breast cancer. Cancer Manag Res, 6:253 - 259, 2014. 
[16] Balikian JP, Jochelson MS, Bauer KA, Sharkin AT, Garnik MB, and Canellos GP. Pulmonary complications of chemotherapy regimens containing bleomycin. AJR Am Roentgenol, $139: 253-259,1982$.

[17] Bellamy EA, Husband JE, Blaquiere RM, and Law MR. Bleomycin-related lung damage: CT evidence. Radiology, 156:155 - 158, 1985.

[18] Rosenow EC and Limper AH. Drug-induced pulmonary disease. Semin Respir infect, 10:86-95, 1995.

[19] Schwarz MI and Fontenot AP. Drug-induced diffuse alveolar hemorrahge syndromes and vasculitis. Clin Chest Med, 25:133 - 140, 2004.

[20] Greenspon AJ, Kidwell GA, Hurley W, and Mannion J. Amiodarone-related postoperative adult respiratory distress syndrome. Circulation, 84 (5 Suppl):III:407 - 415, 1991.

[21] O'Donnell AE, Mappin FG, Sebo TJ, , and Tazelaar H. Interstitial pneumonitis associated with "crack" cocaine abuse. Chest, 100:1155 - 1157, 1991.

[22] Krous HF and Hamlin WB. Pulmonary toxicity due to bleomycin. report of a case. Arch Pathol, 95:407 - 410, 1973.

[23] Piccart MJ, Klijn J, Paridaens R, Nooij M, Mauriac L, Coleman R, Bontenbal M, Awada A, Selleslag JS, Van Vreckem A, and Van Glabbeke M. Corticosteroids significantly delay the onset of docetaxel-induced fluid retention: Final results of a randomized study of the european organization for research and treatment of cancer investigational drug branch for breast cancer. J Clin Oncol, 15:3149 - 3155, 1997.

[24] Semb KA, Aamdal S, and Oian P. Capillary protein leak syndrome appears to explain fluid retention in cancer patients who receive docetaxel treatment. J Clin Oncol, 16:3426 $-3432,1998$.

[25] Sobol SE, Keswani S, Parvadia JK, and Potsic WP. Effect of corticoisteriod-antibiotic agents on granulation tissue in a murine model. Arch Otolaryngol Head Neck Surg, 131:330 $-335,2005$. 
[26] Richardson DW and Dodge GR. Dose-dependent effects of corticoisteriods on the expression of matrix-related genes in normal and cytokine-treated articular chondrocytes. Inflamm Res, 52:39 - 49, 2003.

[27] Spector UWS. Handbook of toxicology, volume 1. The National Academy of Sciences, the National Research Council, 1956.

[28] Green MR. Pulmonary toxicity of antineoplastic agents. West J Med, 127:292 - 298, 1977.

[29] de Lange DW and Meulenbelt J. Do corticosteroids have a role in preventing or reducing acute toxic lung injury caused by inhalation of chemical agents? Clin Toxicol, 49:61 71, 2011.

[30] Wigenstam E, Jonasson S, Koch B, and Bucht A. Corticosteroid treatment inhibits airway hyperresponsiveness and lung injury in a murine model of chemical-induced airway inflammation. Toxicology, 15:66 - 71, 2012.

[31] Hünten MC and Kramer BW. Patterns and etiology of acute and chronic lung injury: insights from experimental evidence. Chin J Contemp Pediatr, 16:448 - 459, 2014.

[32] GuttmannJ, EberhardL, Wolff G, Bertschmann W, Zeravik J, and Adolph M. Maneuverfree determination of compliance and resistance in ventilated ARDS patients. Chest, 102:1235 - 1242, 1992.

[33] Otis A, Fenn W, and Rahn H. The mechanics of breathing in man. J Appl Physiol, 2:592 -607, 1950.

[34] Sharp JT, Henry JP, Sweany SK, Meadows WR, and Pietras RJ. Total respiratory inertance and its gas and tissue components in normal and obese men. $J$ Clin Invest, 43:503 - 509, 1964.

[35] Bates JHT, Irvin CG, Farré R, and Hantos Z. Oscillation mechanics of the respiratory system. Compr Physiol, 1:1233 - 1272, 2011.

[36] Hantos Z, Daroczy B, Suki B, Nagy S, and Fredberg JJ. Input impedance and peripheral inhomogeneity of dog lungs. J Apply Physiol, 72:168 - 178, 1992. 
[37] Ito S, Ingenito EP, Arold SP, Parameswaran H, Tgavalekos NT, Lutchen KR, and Suki B. Tissue heterogeneity in the mouse lung: effects of elastase treatment. J Apply Physiol, 97:204 - 212, 2004.

[38] Gundersen H, Bendtsen T, Korbo L Korbo L, Marcusen N, Moller A, Nielsen K, Nyengaard J, Pakkenberg B, Sorensen F, Vesterby A, and West M. Some new, simple and efficient stereological methods and their use in pathological research and diagnosis. APMIS, 96:379 $-394,1988$.

[39] Irvin CG and Bates JHT. Measuring the lung function in the mouse: the challenge of size. Respir Res, 4:1 - 9, 2003.

[40] Fagundes DJ and Taha MO. Modelo animal de doença: critérios de escolha e modelos animais de uso corrente. Acta Cirurgica Brasileira, 19:59 - 65, 2004.

[41] Schimidt A and Weber OS. Animal Testing in infectology, volume 9. Karger, www.karger.com, 2001.

[42] Limjunyawing N, Fallica J, Horton MR, and Mitzner W. Measurement of the pressurevolume curve in mouse lungs. J Vis Exp, 95, 2015.

[43] Delaval M, Boland S, Solhonne B, Nicola MA, Mornet S, Baeza-Squiban A, Sallenave JM, and Garcia-Verdugo I. Acute exposure to silica nanoparticles enhances mortality and increases lung permeability in a mouse model of pseudomonas aeruginosa pneumonia. Part Fibre Toxicol, 1:doi:10.1186/s12989-014-0078-9, 2015.

[44] Li F, Guo CJ, Huang CC, Yu G, Brown SM, Xu S, and Liu Q. Transient receptor potential A1 activation prolongs isoflurane induction latency and impairs respiratory function in mice. Anesthesiology, 2, 2015.

[45] Bates JHT and Irvin CG. Measuring lung function in mice: the phenotyping uncertainty principle. J Appl Physiol, 94:1297 - 1306, 2003.

[46] Woodward EJ and Twelves C. Scheduling of taxanes: a review. Curr Clin Pharmacol, $3: 226-231,2010$. 
[47] Rowinsky EK. The taxanes: dosing and scheduling. Oncology (Williston Park), 11 (3 Suppl 2):7 - 19, 1997.

[48] Hawthorn J and Cunningham D. Dexamethasone can potentiate the anti-emetic action of a 5HT3 receptor antagonist on cyclophosphamide induced vomiting in the ferret. $\mathrm{Br}$ J Cancer, 1:56-60, 1990.

[49] Shi K, Jiang J, Ma T, Xie J, Duan L, Chen R, Song P, Yu Z, Liu C, Zhu Q, and Zheng J. Dexamethasone attenuates bleomycin-induced lung fibrosis in mice through TGF- $\beta$, Smad3 and JAK-STAT pathway. Int J Clin Exp Med, 7(9):2645 - 2650, 2014.

[50] Fisher AB, DuBois AB, and Hyde RW. Evaluation of the forced oscillation technique for the determination of resistance to breathing. J Clin Invest, 47:2045 - 2057, 1968.

[51] DuBois AB, Brody AW, Lewis DH, and Burgess JR BF. Oscillation mechanics of lungs and chest in man. J Appl Physiol, 8:587 - 594, 1956.

[52] McGover TK, Robichaud A, Fereydoonzad L, Schuessler TF, and Martin JG. Evaluation of respiratory system mechanics in mice using the forced oscillation technique. $J$ Vis Exp, $75: 1-12,2013$.

[53] Costa AA, ACD Faria, AJ Lopes, Jansen JM, and Melo PL. Sensibilidade e especificidade da técnica de oscilações forçadas no diagnóstico precoce da DPOC. Pulmão RJ, 2/4:70 $75,2008$.

[54] Pride NB. Forced oscillation techniques for measuring mechanical properties of the respiratory system. Thorax, 47:317 - 320, 1992.

[55] Peslin R, Silva JF, Duvivier C, and Chabot F. Respiratory mechanics studied by forced oscillations during artificial ventilation. Eur Resp J, 6:772 - 784, 1993.

[56] Demedts M, Noord JAV, and Woestijne KPVD. Clinical applications of forced oscillation technique. Chest, 26:602 - 608, 2005.

[57] Oostveen E, MacLeod D, Lorino H, Farré R, Hantos Z, Desager K, and Marchal F; ERS Task Force on Respiratory Impedance Measurements. The forced oscillation technique in 
clinical practice: methodology, recommendations and future developments. Eur Respir $J, 22: 1026-1041,2003$.

[58] Faria ACM, Lima AN, Lopes AJ, Jansen JM, and Melo PL. Técnica de oscilações forçadas na avaliação funcional de pacientes com fibrose cística com idade superior a 18 anos. Pulmão RJ, 19:2 - 7, 2010.

[59] Barakat R Hess L and, Tian C, Ozols RF, and Alberts DS. Weight change during chemotherapy as a potential prognostic pactor for stage III epithelial ovarian carcinoma: A Gynecologic Oncology Group Study. Gynecol Oncol, 107:260 - 265, 2007.

[60] Andreyev HJN, Norman AR, Oates J, and Cunningham D. Why do patients with weight loss have a worse outcome when undergoing chemotherapy for gastrintestinal malignancies? Eur J Cancer, 34:503 - 509, 1998.

[61] Grosvenor RD, Bulcavage L, and Chebowski RT. Symptoms potentially influencing weight loss in a cancer population. Correlations with primary site, nutritional status and chemotherapy administration. Cancer, 63:330 - 334, 1989.

[62] Gil KM, Frasure HE, Hopkins MP, Jenison EL, and von Gruenigen VE. Body weight and composition changes in ovarian cancer patients during adjuvant chemotherapy. Gynecol Oncol, 103:247 - 252, 2006.

[63] Sanofi-Aventis Canada Inc., 2905 Place Louis-R.-- Renaud Renaud Laval (Québec). Product Monograph Taxotere, August 2013.

[64] Sarcev T, Secen N, Sabo A, and Povazan D. Influence of dexamethasone on appetite and body weight in lung cancer patients. Med Pregl, 61:571 - 575, 2008.

[65] Inui A. Cancer anorexia-cachexia syndrome: current issues in research and management. CA Cancer J Clin, 52:72 - 91, 2002.

[66] Elamin E. Dietary and pharmacological management of severe catabolic conditions. Am J Med Sci, 342:513 - 518, 2011.

[67] Rosalyn M, Stanbury, and Elizabeth M Graham. Systemic corticosteroid therapy - side effects and their management. Br J Ophthalmol, 82:704 - 708, 1998. 
[68] Salminen E, Bergman M, Huhtala S, and Ekholm E. Docetaxel: standard recommended dose of $100 \mathrm{mg} / \mathrm{m}^{2}$ is effective but not feasible for some metastatic breast cancer patients heavily pretreated with chemotherapy - A phase II single-center study. J Clin Oncol, $17: 1127-1131,1999$.

[69] Levitzky MG. Pulmonary physiology. Lange, seventh edition edition, 2003.

[70] Araujo BB, Dolhnikoff M, Silva LF, Elliot J, Lindeman JH, Ferreira DS, Mulder A, Gomes HA, Fernezlian SM, James A, and Mauad T. Extracellular matrix components and regulators in the airway smooth muscle in asthma. Eur Resp J, 32:61 - 69, 2008.

[71] Katzenstein AL and Myers JL. Idiopathic pulmonary fibrosis clinical relevance of pathologic classification. Am J Respir Crit Care Med, 157:1301 - 1315, 1998.

[72] Eric B Meltzer and Paul W Noble. Idiopathic pulmonary fibrosis. Orphanet J Rare Dis, $3: 2-15,2008$.

[73] Blaauboer ME, Boeijen FR, Emson CL, Turner SM, Zandieh-Doulabi B, Smit TH Hanemaaijer R and, Stoop R, and Everts V. Extracellular matrix proteins: A positive feedback loop in lung fibrosis? Matrix Biol, 34:170 - 178, 2004.

[74] Behr J, Demedts M, Buhl R, Costabel U, Dekhuijzen RP, Jansen HM, MacNee W, Thomeer M, Wallaert B, Laurent F, Nicholson AG, Verbeken EK, Verschakelen J, Flower CD, Petruzzelli S, De Vuyst P, van den Bosch JM, Rodriguez-Becerra E, Lankhorst I, Sardina M, and Boissard G; IFIGENIA study group. Lung function in idiopathic pulmonary fibrosis - extended analyses of the IFIGENIA trial. Respir Res, 10:2 - 9, 2009.

[75] Schwaiblmair M, Behr W, Haeckel T, Märkl B, Foerg W, and Berghaus T. Drug induced interstitial lung disease. Open Respir Med J, 6:63-74, 2012.

[76] Mark R and Green MD. Pulmonary toxicity of antineoplastic agents. West J Med, 127:292 $-298,1977$.

[77] Rosenow EC and Limper AH. Drug-induced pulmonary disease. Semin Respir infect, 10:86 - 95, 1995. 
[78] Valeyre D and Musungayi JM. Granulomatous interstitial lung diseases. Rev Prat, 64:946 $-948,2014$.

[79] Dunsford ML, Mead GM, Bateman AC, CooK T, and Tung K. Severe pulmonary toxicity in patients treated with a combination of docetaxel and gemcitabine for metastatic transitional cell carcinoma. Ann Oncol, 10:943 - 947, 1999.

[80] Grande C, Villanueva MJ, Huidobro G, and Casal J. Docetaxel-induced intersticial pneumonitis following non-small-cell lung cancer treatment. Clin Transl Oncol, 9:578 - 581, 2007.

[81] Ho MY and Mackey JR. Presentation and management of docetaxel-related adverse effects in patients with breast cancer. Cancer Management and Research, 6:253 - 259, 2014.

[82] Merad M, Cesne AL, Baldeyrou P, Mesurolle B, and Chevalier TL. Docetaxel and intersticial pulmonary injury. Ann Oncol, 8:191 - 194, 1997.

[83] Suki B and Bates JH. Extracellulkar matrix mechanics in lung parenchymal diseases. Respir Physiol Neurobiol, 163:33 - 43, 2008.

[84] Turino GM. The lung parenchyma - a dynamic matrix. Am Rev Respir Dis, 132:1324$1334,1985$.

[85] Laurent GJ. Lung collagen: more than scaffolding. Thorax, 41:418 - 428, 1986.

[86] Koh Y. Update in acute respiratory distress syndrome. J Intensive Care, 2:2 - 6, 2014.

[87] Glassroth JL, Bernardo J, Lucey EC, Center DM, Jung-Legg YJ, and Snider GL. Intersticial pulmonary fibrosis induced in hmasters by intratracheally administered chrysotile asbestos. histology, lung mechanics and inflammatory events. Am Rev Respir Dis, 130:242 $-248,1984$.

[88] Manali ED, Moschos C, Triantafilidou C, Kotanidou A, Psallidas I, Karabela SP, Roussos C, Papiris S, Armaganidis A, Stathopoulos GT, and Maniatis NA. Static and dynamic mechanics of the murine lung after intratracheal bleomycin. BMC Pulm Med, 11, 2011. 
[89] Taylor MD, Van Dyke K, Bowman LL, Miles PR, Hubbs AF, Mason RJ, and Reasor MJ Shannon K. A characterization of amiodarone-induced pulmonary toxicity in F344 rats and identification of surfactant protein-D as a potential biomarker for the development of the toxicity. Toxicol Appl Pharmacol, 15:182 - 190, 2000.

[90] Alsamarai S, Charpidou AG, Matthay RA, Confeld D, Syrigos KN, and Saif MW. Pneumonitis related to docetaxel: case report and review of the literature. In vivo, 23:635 638, 1997.

[91] A Serpa Neto, Tobias-Machado M, Kaliks R, Wroclawski ML, Pompeo AC, and Giglio Del. Ten years of docetaxel-based therapies in prostate adenocarcinoma: a systematic review and meta-analysis of 2244 patients in 12 randomized clinical trials. Clin Genitourin Cancer, 9:115 - 123, 2011.

[92] Chen C and Raghunath M. Focus on collagen: in vitro systems to study fibrogenesis and antifibrosis state of the art. Fibrogenesis Tissue Repair, 2:doi:10.1186/1755-1536-2-7, 2009.

[93] Rai K, Tripathi K, Sharma D, and Shukla VK. Apoptosis: a basic physiologic process in wound healing. Int J Low Extrem. Wound, 4:138 - 144, 2005.

[94] Johnson A and DiPietro LA. Apoptosis and angiogenesis: an evolving mechanism for fibrosis. FASEB J, 27:3893 - 3901, 2013.

[95] T Kisseleva and Brenner DA. Mechanisms of fibrogenesis. Exp Biol Med, 233:109 - 122, 2008 .

[96] Laplante P, Sirois I, Raymond MA, Kokta V, Béliveau A, Prat A, Pshezhetsky AV, and Hébert MJ. Caspase- 3-mediated secretion of connective tissue growth factor by apoptotic endothelial cells promotes fibrosis. Cell Death Differ, 17:291 - 303, 2010.

[97] Wang L, Scabilloni JF, Antonini JM, Rojanasakul Y, Castranova V, and Mercer R. Induction of secondary apoptosis, inflammation, and lung fibrosis after intratracheal instillation of apoptotic cells in rats. Am J Physiol Lung Cell Mol Physiol, 290:L696 - L702, 2006. 
[98] Piccart MJ, Klijn J, Paridaens R, Nooij M, Mauriac L, Coleman R, Bontenbal M, Awada A, Selleslags J, Van Vreckem A, and Van Glabbeke M. Corticosteroids significantly delay the onset of docetaxel-induced fluid retention: Final results of a randomized study of the european organization for research and treatment of cancer investigational drug branch for breast cancer. J Clin Oncol, 15:3149 - 3155, 1997.

[99] de Lange DW and Meulenbelt J. Do corticosteroids have a role in preventing or reducing acute toxic lung injury caused by inhalation of chemical agents? Clin Toxicol (Phila), 2011:61 - 71, 2011.

[100] Ali R, Mittal G, Ali R, Kumar M, Kishan Khar R, Ahmad FJ, and Bhatnagar A. Development, characterisation and pharmacoscintigraphic evaluation of nano-fluticasone propionate dry powder inhalation as potential antidote against inhaled toxic gases. J Microencapsul, 30:546 - 558, 2013.

[101] Jonassona S, Wigenstama E, Kocha B, and Buchta A. Early treatment of chlorineinduced airway hyperresponsiveness and inflammation with corticosteroids. Toxicol Appl Pharmacol, 271:168 - 174, 2013.

[102] Wang LP, Wang YW, Wang BZ, Sun GM, Wang XY, and Xu JL. Expression of Interleukin-17A in Lung Tissues of Irradiated Mice and the Influence of Dexamethasone. Scientific WorldJournal, pages 1 - 7, 2014.

[103] Nagata S, Ueda N, Yoshida Y, Matsuda H, and Maehara Y. Severe interstitial pneumonitis associated with the administration of taxanes. J Infect Chemothe, 16:340 - 344, 2010.

[104] Leimgruber K, Negro R, Baier S, Moser B, Resch G, Sansone S, Adami M, Zanon P, Graiff C, Egarter-Vigl E, and Wiedermann CJ. Fatal interstitial pneumonitis associated with docetaxel administration in a patient with hormone-refractory prostate cancer. Tumori, $92: 542-544,2006$.

[105] Hughes BG and Stuart-Harris R. Docetaxel-induced myositis: report of a novel side effect. Intern Med J, 35:369 - 370, 2005. 
[106] Ardavanis AS, Ioannidis GN, and Rigatos GA. Acute myopathy in a patient with lung adenocarcinoma treated with gencitabine and docetaxel. Anticancer Res, 25:523-526, 2005.

[107] Kliment CR, Englert JM E, Crum LP, and Oury TD. A novel method for accurate collagen and biochemical assessment of pulmonary tissue utilizing one animal. Int $J$ Clin Exp Pathol, 4:349 - 355, 2011.

[108] Junqueira LC, Bignolas G, and Brentani RR. Picrosirius staining plus polarization microscopy, a specific method for collagen detection in tissue sections. Histochem J, 11:447 $-455,1979$.

[109] Woessner JF. The determination of hydroxyproline in tissue and protein samples containing small proportions of this imino acid. Arch Biochem Biophys, 93:440 - 447, 1961.

[110] Neuman RE and Logan MA. The determination of hydroxyproline. J Biol Chem, 184:299 $-306,1950$.

[111] Last JA and Reiser KM. Collagen biosynthesis. Environ Health Perspect, 55:169 - 177, 1984 . 
$\prod_{\text {Apêndice }}$

Aprovação da Comissão de Ética no Uso de Animais 

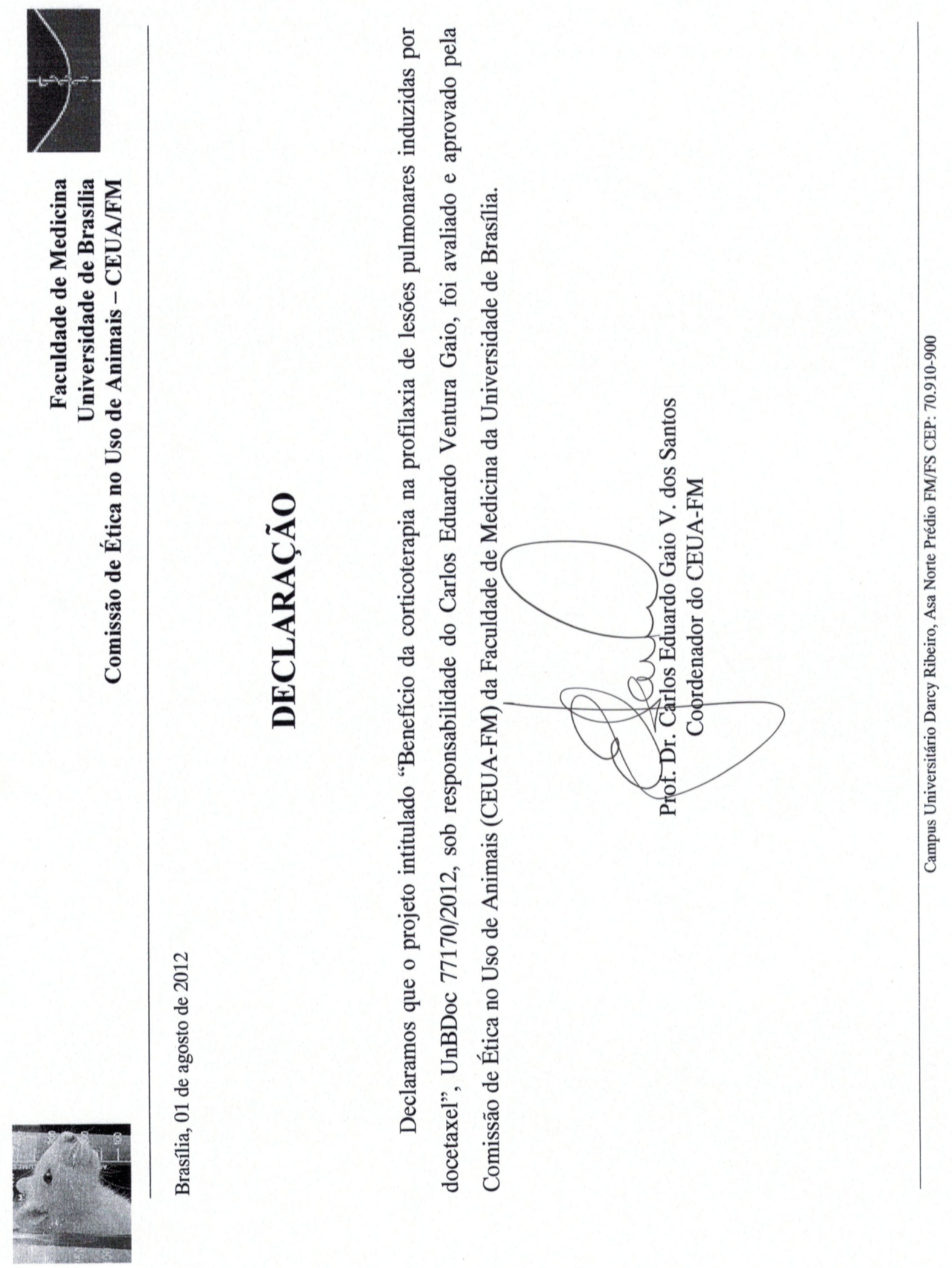